\title{
Function of exosomes in neurological disorders and brain tumors
}

\author{
Lan Xiao, Sangeetha Hareendran, Y. Peng Loh \\ Section on Cellular Neurobiology, Eunice Kennedy Shriver, National Institute of Child Health and Human Development, National \\ Institutes of Health, Bethesda, MD 20892, USA.

\begin{abstract}
Correspondence to: Dr. Y. Peng Loh, Section on Cellular Neurobiology, National Institute of Child Health and Human Development, National Institutes of Health, Convent Drive, BIdg 49, Rm 6A-10, Bethesda, MD 20892, USA. E-mail:
\end{abstract} \\ lohp@mail.nih.gov
}

How to cite this article: Xiao L, Hareendran S, Loh YP. Function of exosomes in neurological disorders and brain tumors. Extracell Vesicles Circ Nucleic Acids 2021;2:55-79. https://dx.doi.org/10.20517/evcna.2021.04

Received: 10 Feb 2021 First Decision: 4 Mar 2021 Revised: 15 Mar 2021 Accepted: 19 Mar 2021 Available online: 30 Mar 2021

Academic Editor: Tsuneya Ikezu Copy Editor: Yue-Yue Zhang Production Editor: Yue-Yue Zhang

\begin{abstract}
Exosomes are a subtype of extracellular vesicles released from different cell types including those in the nervous system, and are enriched in a variety of bioactive molecules such as RNAs, proteins and lipids. Numerous studies have indicated that exosomes play a critical role in many physiological and pathological activities by facilitating intercellular communication and modulating cells' responses to external environments. Particularly in the central nervous system, exosomes have been implicated to play a role in many neurological disorders such as abnormal neuronal development, neurodegenerative diseases, epilepsy, mental disorders, stroke, brain injury and brain cancer. Since exosomes recapitulate the characteristics of the parental cells and have the capacity to cross the blood-brain barrier, their cargo can serve as potential biomarkers for early diagnosis and clinical assessment of disease treatment. In this review, we describe the latest findings and current knowledge of the roles exosomes play in various neurological disorders and brain cancer, as well as their application as promising biomarkers. The potential use of exosomes to deliver therapeutic molecules to treat diseases of the central nervous system is also discussed.
\end{abstract}

Keywords: Extracellular vesicles, neurodegenerative disorders, glioblastoma, Alzheimer's disease, neurodevelopment 


\section{INTRODUCTION}

Extracellular vesicles (EV) were first described in 1967 as "platelet dusts" in plasma ${ }^{[1]}$. Currently, EVs are divided into three main categories based on the origination and size: exosome derived from endosomes, ranging from 40 to $100 \mathrm{~nm}$ in diameter; microvesicle/shedding particles from plasma membrane, which are larger than $100 \mathrm{~nm}$ in diameter; apoptotic bodies from plasma membrane, which are 1-5 $\mu \mathrm{m}$ in diameter ${ }^{[2,3]}$. In this review, while most of the literature cited has used the term exosome, the degree of characterization of the exosomes in the various papers varied; most have met the guidelines such as size by NTA, exosomal markers and electron microscopy or zeta view, reported for exosomes in MISEV2014 $4^{[4]}$, and others with insufficient characterization to confirm specific identity as exosomes are referred to as extracellular vesicles.

Exosomes, initially described as vesicles released from various types of cultured cells ${ }^{[5]}$, are microvesicles derived from endosomal membranes. Microvesicles were first described by Dr. C. Turbide in 1987 in his study of maturation of sheep reticulocyte. Vesicles obtained after 100,000x g centrifugation were found to contain some characteristic activity of the reticulocyte ${ }^{[6]}$. These vesicles were then further defined as being originated from endosomes, with a diameter from 30 to $100 \mathrm{~nm}^{[7]}$. As a subtype of extracellular vesicles with a bilayer membrane that bud from cell membrane and/or are secreted, exosomes are heterogeneous and influenced by the physiological and pathological conditions of the originating cells. Exosomes are distributed broadly in human secretions and act as intercellular messengers via transferring or exchanging DNA, RNA, and proteins between cells ${ }^{[8,9]}$.

Recently, emerging studies have revealed that exosomes have more complicated facets. They are not just secreted as cellular wastes or by-products, but contain a variety of cargos such as proteins, lipids, and nucleic acids, and exert their function by delivering cargoes to target cells and modulating the bioactivity of recipient cells. Therefore, exosomes serve as a new mode of intercellular communication and play a critical role in biological systems, and pathogenesis of diseases, including those of the central nervous system. In addition, the ability of exosomes to cross the blood-brain barrier makes them ideal therapeutic delivery vehicles and potential biomarkers for neurological disorders ${ }^{[10]}$.

\section{Exosome structure and content}

Exosomes are released from a variety of cell types, and can be found in physiological fluids such as blood ${ }^{[11]}$, cerebrospinal fluid ${ }^{[12]}$, saliva ${ }^{[13]}$, urine ${ }^{[14]}$ and breast milk ${ }^{[15]}$. Exosomes consist of a wide range of molecules such as proteins, lipids and nucleic acids [Figure 1], and reflect the pathophysiology and physiological features of parental cells.

Current studies have shown that exosome membranes are enriched in sphingomyelin, phosphatidylserine, cholesterol, and ceramides. Exosomes contain a variety of proteins such as tetraspanins (CD9, CD63, CD81), endosomal origin proteins (ALIX,TSG 101), heat-shock proteins (HSP70, HSP90), enzymes(GAPDH, nitric oxide synthase, catalase), receptor (EGFR), major histocompatibility complex I-II, adhesion proteins, integrins, cytoskeleton proteins (actin, gelsolin, myosin, tubulin) and cytosolic proteins ${ }^{[16,17]}$. Irrespective of the origin, certain proteins such as TSG101, HSP70, CD81 and C63 are exclusively involved in the biogenesis of exosomes, and thus generally used as exosome markers. However, since the purity of the exosomes isolated has not been fully assessed in some studies, it is possible that skeletal proteins e.g., actin, myosin and tubulin reported to be present in exosomes may be contaminants of the exosome-enriched fraction. In addition, lipid components within exosomes can be incorporated into recipient cells and mediate complex biological effects ${ }^{[2]}$. Moreover, RNA sequencing showed that mRNA and microRNA are also abundant in exosomes from human plasma, in addition to other species of RNA such as ribosomal RNA, small nuclear RNA, transfer $\mathrm{RNA}^{[2,18]}$ and long $\mathrm{RNA}^{[19]}$ that maintain critical 


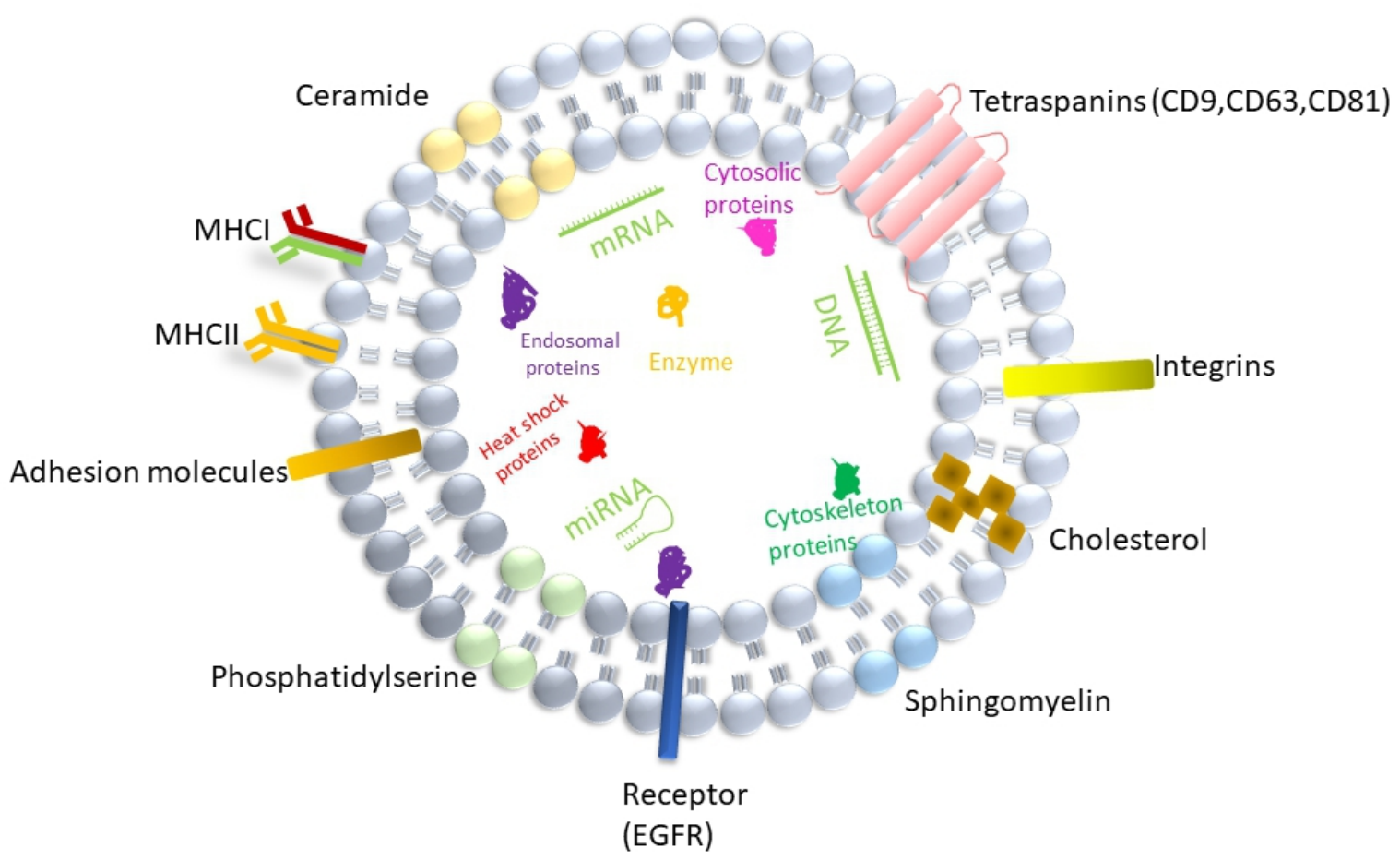

Figure 1. Structure and composition of exosome. Exosome is a lipid bilayer structure that contains lipids, proteins and nucleic acids. Sphingomyelin, phosphatidylserine, cholesterol and ceramides are highly distributed on the membrane. In addition, exosomes also

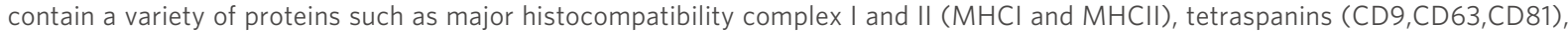
endosomal origin proteins (ALIX,Tsg101), heat shock proteins (HSP70,HSP90), enzymes(GAPDH, nitric oxide synthase, catalase), receptor(EGFR), adhesion proteins, integrins, cytoskeleton proteins (actin, gelsolin, myosin, tubulin) and cytosolic proteins, as well as RNA, miRNA and DNA.

biological functions.

\section{Exosome biogenesis, secretion, and uptake}

Exosome biogenesis is a complicated process that involves a variety of signaling cascades. Exosomes are formed by multi-vesicular bodies (MVBs) which are late endosomes. The membrane of MVB buds inward to form intraluminal vesicles (ILVs) with components derived from either endocytic pathway or secretory (ER/Golgi) pathway, into the endosomal lumen ${ }^{[20]}$ [Figure 2]. Following accumulation of vesicles, MVBs will be either transported to lysosomes for degradation ${ }^{[21]}$ or fused with plasma membrane to release ILVs into extracellular space as exosomes ${ }^{[22]}$. However, how the cargo is sorted to ILVs and how formation and release of exosomes are regulated by internal and external factors are still not fully understood.

Recent studies indicate that both endosomal sorting complex transport (ESCRT)-dependent and ESCRTindependent pathways are involved in the formation and secretion of exosomes ${ }^{[2,23]}$. ESCRT consists of four major protein complexes, including ESCRTo, ESCRT-I, ESCRT-II, ESCRTIII and associated AAA ATPase Vps4 Complex. In an analysis with RNA interference screen targeting 23 components of ESCRT and associated proteins, it was found that seven ESCRT proteins contributed to the release of exosomes ${ }^{[24]}$ : Knockdown of ESCRT-0 proteins Hrs and TSG101, ESCRT-I protein STAM1 decreased the secretion of exosomes; in contrast, knockdown of ESCRT-III proteins CHMP4C, VPS4B,VTA1 and ALIX increased the secretion of exosomes. Further studies revealed that ESCRT-0 sequestered ubiquitinated proteins into 


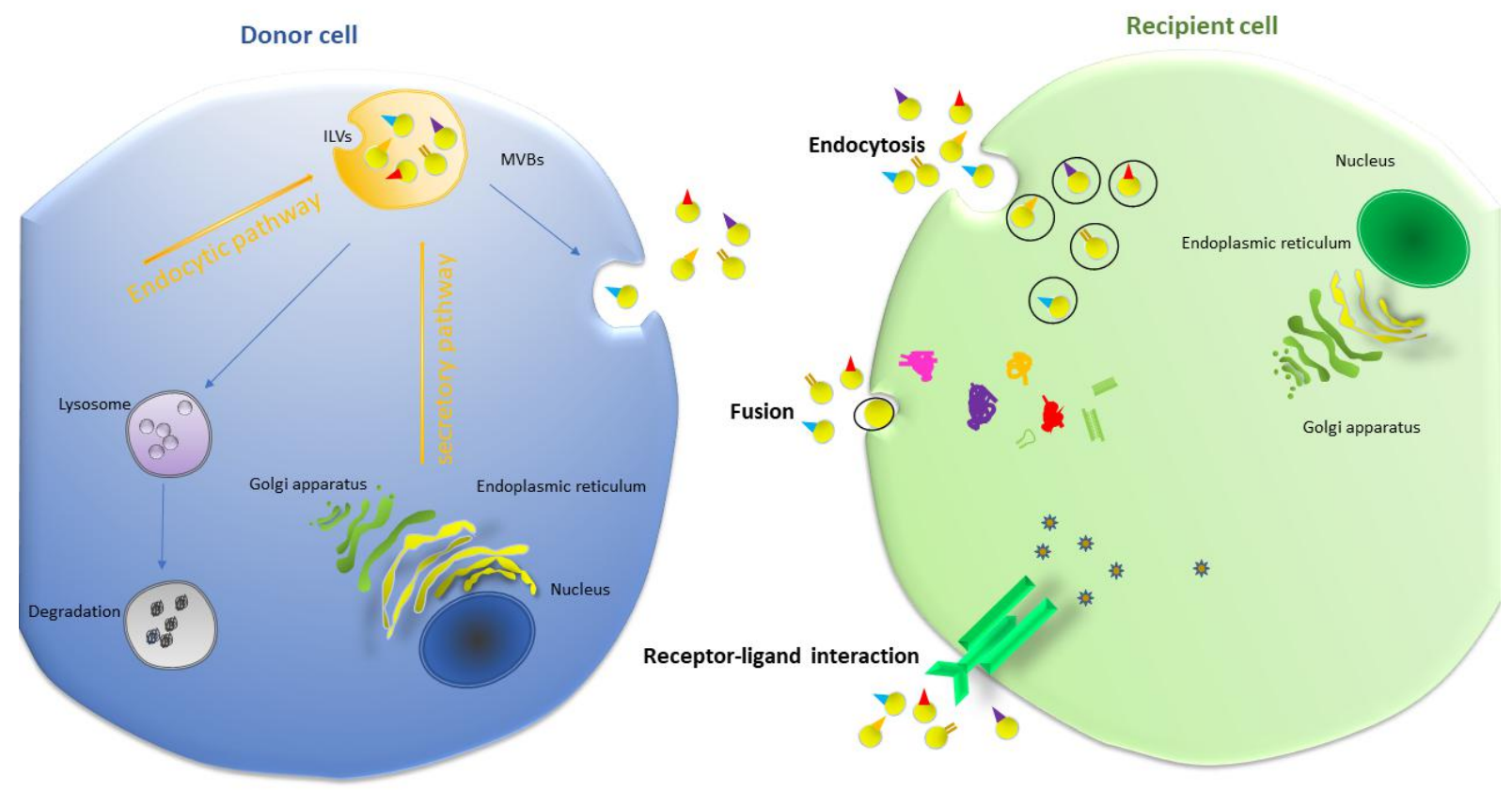

Figure 2. Biogenesis of exosome. The biogenesis of exosomes occurs when multivesicular bodies uptake intraluminal vesicles formed from either endocytic pathway or ER/Golgi secretory pathway. Then, MVBs either fuse with cellular membrane to release exosomes, or fuse with lysosomes for cargo degradation. After releasing into extracellular space, exosomes act as a mediator of intercellular communication through being taken up by recipient cells via endocytosis, fusion or receptor-ligand interaction. This process can be either paracrine or endocrine in manner. MVBs: Multivesicular bodies.

specific domains of endosomal membrane, and then combined with ESCRT-III after crosslinking with ESCRT-I and ESCRT-II complex. ESCRT-III finally promotes intraluminal vesicle formation via facilitating the budding process and separation from the MVB membrane ${ }^{[25]}$. Interestingly, syndecan heparan sulphate proteoglycans and their cytoplasmic adaptor, syntenin, have been shown to regulate exosome formation via modulating ALIX through LYPX(n)L motifs to facilitate the intraluminal budding of endosomal membranes $^{[26]}$. These results suggest ESCRT is critical for cargo sorting, multivesicular body formation, and the budding process ${ }^{[27]}$.

Conversely, a large amount of evidence indicates that exosomes can also be formed and released in an ESCRT-independent manner. Studies showed that when four major ESCRT complexes were simultaneously silenced, ILVs were still observed in MVBs, suggesting existence of a ESCRT-independent mechanism ${ }^{[28]}$. In addition, other proteins and lipids are also involved in the regulation of exosome biogenesis and secretion. Tetraspanins, transmembrane proteins that are highly distributed in exosomes, contributed to the ESCRTindependent exosome release ${ }^{[29]}$ : overexpression of tetraspanins CD9 and CD82 increased catenin in exosomes released from HEK293 cells ${ }^{[30]}$; tetraspanin Tspans promoted recruitment of specific proteins and mRNA into exosomes, such as CD106 and CD49d that are critical for exosome-endothelial cell binding and internalization $^{[31]}$; Tetraspanin $\mathrm{CD} 63$ has also been reported to be involved in exosome biogenesis as evidenced by decreased small vesicle secretion after (CRISPR)/Cas9 knockout of the CD63 gene in HEK293 cells $^{[32]}$; finally, tetraspanin-enriched microdomains and tetraspanin CD81 are important for sorting specific receptors and components toward exosomes ${ }^{[33]}$. Furthermore, ceramides have been shown to enhance domain-induced budding due to its activity to promote negative curvature of endosomal membrane ${ }^{[34]}$. Rab guanosine triphosphatases (GTPases) such as Rab27a/b ${ }^{[35]}$, and Rab35 and GTPase-activating proteins TBC1D10A-C have also been reported to contribute to the process of exosome secretion pathway ${ }^{[36]}$. 
Interestingly, cellular homeostasis also can affect exosome secretion. For example, increased intracellular $\mathrm{Ca}^{2+}$ induced more exosome secretion in K562 cells, a hematopoietic cell line ${ }^{[37]}$. Environmental pH has also been shown to influence exosome secretion ${ }^{[38]}$. In addition, cellular stress such as irradiation ${ }^{[3,40]}$, cisplatin treatment ${ }^{[41]}$, exposure to hypoxia ${ }^{[42]}$ and ER stress ${ }^{[43]}$ can all increase exosome release. Increased release of waste via exosomes might be a natural response to stress, but also could be an approach for cells to communicate with each other under pathological conditions. Particularly, many neurodegenerative disorders are associated with lysosomal or autophagy dysfunctions and aggregations of pathological proteins; exosomes could play a critical role in such neuropathogenesis ${ }^{[23]}$.

As a critical mediator for intercellular communication, exosomes are taken up by recipient cells via three major methods: receptor-ligand interaction, fusion with plasma membrane, and endocytosis by phagocytosis ${ }^{[17]}$ [Figure 2]. For receptor-ligand uptake, the molecular mechanism remains elusive. Current studies revealed that Tim1- or Tim4-expressing Ba/F3 B cells could bind exosomes via phosphatidylserine, suggesting Tim4 and Tim1 are possible phosphatidylserine receptors for exosomes ${ }^{[44]}$. Another study implied that intercellular adhesion molecule 1 (ICAM-1) is critical for mature exosomes to prime naive T cells ${ }^{[45]}$. Fusion with plasma membrane was supported by studies showing exosomes can be taken up by melanoma cells through membrane fusion ${ }^{[17]}$. Interestingly, K562 or MT4 cells-derived exosomes were internalized more efficiently by phagocytes than non-phagocytic cells, implying that phagocytosis may play a unique role in exosome-cell interactions and uptake ${ }^{[46]}$.

Strikingly, numerous studies have indicated that exosomes are critical for communication between different neural cell types. Microglia could specifically internalize oligodendrocyte-derived exosomes by macropinocytosis, and most of these microglia were MHC class II negative and did not activate immunological responses ${ }^{[47]}$. Neurons have been shown to be able to internalize oligodendrocyte-derived exosomes by endocytosis ${ }^{[48]}$. In addition, crosstalk between neuron and glia also occurs through exosomes. Exosomes from stressed astrocytes that were exposed to oxygen and glucose deprivation could produce neuroprotective effects against oxidative stress in neurons and this effect was dependent on Prion protein $^{[49]}$. It has been demonstrated that exosomes are internalized via several mechanisms and the uptake depends on the type of recipient cells. For example, exosomes derived from neuroblastoma bound to neurons and glial cells, but were preferentially endocytosed by glial cells; exosomes derived from cortical neurons were exclusively bound and endocytosed by neurons ${ }^{[50]}$. Indeed, a lot more studies are needed to understand the specificity and molecular mechanism of exosome uptake among different neuronal and glial cell types.

\section{Exosome-mediated intercellular communication in the nervous system}

In 1980, exosomes were still believed to be a means of disposing cell debris ${ }^{[1]}$. However, emerging studies have indicated that exosomes also play multiple roles in biological activities such as cell-to-cell communication, which was traditionally considered to be mediated by gap junction, receptor/ligand, or electrical and chemical signals ${ }^{[2,53]}$. Studies showed that exosome release was increased from cortical neurons by treatment with GABA receptor antagonist, bicucullin; however, this increase was blocked by either AMPA receptor antagonist, CNQX, or NMDA receptor antagonist, MK-801, suggesting exosome release was regulated by glutamatergic synaptic activity ${ }^{[54]}$.

Oligodendrocytes secrete exosomes into extracellular space that can inhibit morphological differentiation in oligodendrocytes and myelin formation, and this effect could be blocked with inhibitors of actomyosin contractility. Interestingly, conditioned neuronal medium dramatically reduced secretion of exosomes from oligodendrocytes, suggesting interaction between neurons and oligodendrocytes during myelin 
biogenesis $^{[55]}$. Other studies have shown that microglia could internalize exosomes released from oligodendroglia by macropinocytosis, which was then transferred to late endosomes and lysosomes ${ }^{[4]}$. Conversely, studies have revealed that neurotransmitters could stimulate the release of exosomes from oligodendroglial, which subsequently could be internalized and utilized by neurons ${ }^{[48]}$. Mice with absence of proteolipid protein and 2',3'-cyclic nucleotide 3 '-phosphodiesterase, which are enriched in oligodendroglial exosomes, exhibited axonal degeneration ${ }^{[56]}$. In addition, it was shown that Hsp/Hsc70 exiting from oligodendroglia could be taken up by squid giant axon $^{[57]}$, and this process is likely mediated by exosomes ${ }^{[58]}$.

Neurons also regulate intercellular communication and maintain homeostasis such as neurogenesis and synaptic activity via exosomes. Studies using electron microscopy showed that exosomes were secreted from somato-dendritic compartments of mature cortical neurons, confirming neurons secrete exosomes ${ }^{[54]}$. Exosomes released from primary cortical neurons contained several functional proteins that could regulate synaptic activity, and the release of exosomes was controlled by depolarization ${ }^{[59]}$. Cystatin $\mathrm{C}$ was detected in exosomes released from mouse primary neurons and played a critical role in neuroprotection ${ }^{[60]}$. In addition, studies in Drosophila neuromuscular junction demonstrated that release of exosomal synaptotagmin 4 from presynaptic terminals was crucial for synaptic growth ${ }^{[61]}$. Co-incubation of mouse microglial cell line with PC12 cells enhanced the elimination of degenerating neurites in PC12, and treatment with PC12-derived exosomes significantly increased the pruning activity of microglia ${ }^{[62]}$. In addition, exosomes secreted from primary cortical neurons were internalized into astrocytes and upregulated GLT1 proteins ${ }^{[63]}$.

Microglia can also have crosstalk with neurons and modulate neuronal activity through exosomes. Synapsin I has been observed in the exosomes released from glial cells and found to promote neurite outgrowth in hippocampal neurons and survival of cortical neurons ${ }^{[64]}$. Also a group of miRNA, including miR-146a-5p, has been detected in the extracellular vesicles released from microglia, which regulates the expression of important synaptic proteins ${ }^{[6]}$.

All the evidence suggests that exosomes contribute to intercellular communication via internalization by target cells, activating downstream signaling cascades, or releasing components into the extracellular space. However, the precise understanding of the molecular mechanism underlying this process continues to evolve. Since most experiments were performed in vitro, further studies in animal models will open up new perspectives for understanding the function of exosomes in communication in the central nervous system $^{[48]}$.

\section{Role of exosomes in neurodevelopment}

Recent studies have shown that exosomes play an integral role in normal neurodevelopment such as neural plasticity, and contribute to the pathological changes in neurodevelopmental diseases ${ }^{[6]}$. For instance, embryonic cerebrospinal fluid-derived exosomes improved neural stem cell amplification through targeting the rapamycin complex 1 pathway ${ }^{[67]}$. Exosomes also seem to act as a regulator in the niche of mesenchymal stem cell and a modifier of proliferation and differentiation of neural stem cells ${ }^{[68]}$. Exosomes originated from neural progenitor cells have been shown to promote neuronal differentiation and facilitate neurogenesis through miR-2 $1 \mathrm{a}^{[69]}$. Exosomes from human induced pluripotent stem cell (hiPSC)-derived neurons increased proliferation in human primary neural cultures in vitro. In parallel with in vitro studies, injection of exosomes purified from DIV9 rodent primary neural cultures into the lateral ventricles of $\mathrm{P} 4$ mouse brains increased neurogenesis in the dentate gyrus of hippocampus ${ }^{[70]}$. On the other hand, studies have shown that exosomes are not only involved in neurogenesis, but also regulate synaptogenesis and neural circuit development. For example, treatment with normal control exosomes could reduce damages 
in neuronal proliferation, differentiation, synaptogenesis, and synchronized firing in methyl-CpG-binding protein 2 (MECP2)-knockdown human primary neural cultures, which is a key gene contributing to abnormal neurodevelopment in Rett syndrome. Further proteomic analysis revealed that normal (control) exosomes may contain critical factors that are crucial for neuronal maturation and synaptogenesis which are absent in MECP2LF exosomes, suggesting the involvement of exosomes in neuronal development. Interestingly, exosomes have been reported to produce therapeutic effects in neurodevelopment disorders in vivo. Intranasal treatment with exosomes derived from mesenchymal stem cells enhanced behavioral autistic-like phenotype such as social vocalization and reduced repetitive behaviors in Shank3B Knockout autism mouse model ${ }^{[71]}$. Recently, extracellular vesicles have been used to encapsulate CRISPR/Cas9 genome editing machinery for delivery to cells. This could be a potentially new approach for delivering Cas9/sgRNA for treating a variety of genetic diseases, including those impacting the nervous system ${ }^{[72,73]}$.

\section{Function of exosomes in neurodegenerative disorders}

As a critical mediator for cell communication, exosomes have been reported to augment the progression of neurodegenerative disorders such as Alzheimer's disease, Parkinson's disease, Prion disease, Amyotrophic lateral sclerosis and Huntington's disease, via delivery of proteins or molecules associated with the pathology of such diseases [Table 1].

\section{Role of exosomes in Alzheimer's disease}

Alzheimer's disease $(\mathrm{AD})$ is one of the most devastating neurodegenerative disorders that cause dementia and decreased cognitive function. It currently affects more than 5 million people in the United States and is expected to rise to about 13.8 million by $2050^{[74,75]}$. Accumulation of amyloid $\beta$-peptide (A $\beta$ ) plaque extracellularly and formation of neurofibrillary tangles from hyperphosphorylated tau intracellularly are pathological hallmarks of AD that generally precede the clinical symptoms ${ }^{[76]}$. Recent studies have revealed that exosomes play very complex roles in $\mathrm{AD}^{[76-79]}$. Both $\mathrm{A} \beta$ peptide and tau are released from exosomes and have been implicated in the propagation of aggregates of these proteins. A recent proteomic and bioinformatics study of exosomal proteins in human iPSC neurons expressing mutant Tau (mTau) revealed many differences with normal exosomes such as the presence of a PP2A phosphatase inhibitor. Their data suggest that mTau exosomes may be able to regulate propagation of phosphorylated tau in vivo and contribute to the neuropathology ${ }^{[80]}$.

It has been reported that neuron-derived exosomes have the ability to confer conformational changes to extracellular $A \beta$, converting these molecules into non-toxic fibrils which promote uptake by microglia ${ }^{[81]}$. Secretion of these neuronal exosomes appears to be regulated by neutral sphingomyelinase 2 and sphingomyelin synthase 2 (SMS2). SMS2 siRNA enhanced exosome secretion and A $\beta$ uptake into microglia and decreased extracellular $A \beta^{[81]}$. Studies in vivo have shown that neuroblastoma-derived exosomes injected into mouse brain trapped $A \beta$ and facilitated the internalization of $A \beta$ into microglia. Continuous injection of these exosomes into amyloid- $\beta$ precursor protein transgenic mice significantly reduced $A \beta$ and $A \beta$ mediated synaptotoxicity in the hippocampus. Further studies revealed that glycosphingolipids that are highly distributed on these exosome membranes are critical for the A $\beta$ binding ${ }^{[82]}$. Another line of study showed that N2a cell-derived exosomes could rescue A $\beta$-mediated disruption of synaptic plasticity via trapping $A \beta$ with cellular prion protein ${ }^{[83,84]}$. Glycosphingolipids on these exosome are important for binding and sequestering $A \beta^{[85]}$. All these studies suggest that exosomes may play an important role in the nervous system. Additionally, studies have suggested that exosomes contain a variety of components that produce neuroprotective effects such as neprilysin ${ }^{[86]}$ and insulin-degrading enzyme that are important for $A \beta$ degradation $^{[87]}$. 
Table 1. Exosome cargo as biomarkers in neurodegenerative disorders

\begin{tabular}{|c|c|c|c|c|}
\hline Name of disease & $\begin{array}{l}\text { Exosome } \\
\text { cargo }\end{array}$ & Pathology & Application & Ref. \\
\hline Alzheimer's disease & $A \beta$ & Neuronal impairment & Early diagnosis & $\begin{array}{l}\text { Saman et al. }{ }^{[99]} \\
, 2012\end{array}$ \\
\hline Parkinson's disease & $\alpha$-syn & Neuronal damage & $\begin{array}{l}\text { Early diagnosis } \\
\text { Monitoring severity of cognitive } \\
\text { impairment }\end{array}$ & $\begin{array}{l}\text { Shi et al. }{ }^{[116]}, 2014 \\
\text { Stuendl et al. }{ }^{[113]} \\
, 2016 \\
\text { Si et al al }{ }^{[117]}, 2019 \\
\text { Jiang et al }{ }^{[118]}, 2020 \\
\text { Niu et al. }{ }^{[119]}, 2020\end{array}$ \\
\hline $\begin{array}{l}\text { Amyotrophic lateral } \\
\text { sclerosis }\end{array}$ & TDP-43 & $\begin{array}{l}\text { Neuronal inflammation and } \\
\text { damage }\end{array}$ & Early diagnosis & Chen et al. ${ }^{[137]}, 2020$ \\
\hline
\end{tabular}

Other studies have provided controversial results which suggest that exosomes might play complicated roles in the development of AD. For example, in APPxPS1 transgenic AD mouse model, intracellular A $\beta$ was found to be colocalized with raft marker flotillin-1, suggesting that $A \beta$ accumulated within multivesicular bodies $^{[88]}$. A minute fraction of $\mathrm{A} \beta$ was subsequently released into extracellular space in association with exosomes $^{[89]}$. Similarly, other studies have shown that amyloid precursor protein (APP), APP-C-terminal fragments, and amyloid intracellular domain were all secreted from exosomes in differentiated neuroblastoma and primary neuronal culture cells ${ }^{[90]}$. In HEK-293-derived exosomes, Holo-APP, Presenilin and APP C-terminal fragments were all detected, and secretion of total APP C-terminal fragments was higher in exosomes derived from retromer deficient cells ${ }^{[91]}$. In addition, intraperitoneal injection of GW4869, a neutral sphingomyelinase 2 inhibitor, significantly decreased brain ceramide, exosome secretion from brain and serum exosome levels, as well as $A \beta 1-42$ plaques in $5 X F A D$ mice ${ }^{[92]}$. In contrast, feeding female mice with ceramide showed a higher load of plaque burden and exosome secretion ${ }^{[93]}$,suggesting an association with exosome levels and A $\beta$ accumulation in plaques. Furthermore, APP, BACE1, PSEN1, PSEN2 and Adam10, and many proteases that have the capacity to splice APP, have also been reported to be released from exosomes ${ }^{[94]}$. Thus, exosomes represent a novel pathway for APP processing and secretion, and amyloid deposition in $\mathrm{AD}$ brain. Interestingly, current research revealed that while during early stage of $\mathrm{AD}$, activation of microglia produced protective effect by increasing phagocytosis and $\mathrm{A} \beta$ clearance ${ }^{[95-97]}$; during late stage of $\mathrm{AD}$, microglia increased the release of exosomes or EV that contained soluble toxic $\mathrm{A} \beta$ and facilitated the progression of $\mathrm{AD}^{[97,98]}$.

Due to the unique characteristics of exosomes in that they recapitulate the features of the originating cells and are able to cross the blood brain barrier, their contents can serve as potential biomarkers for diagnosis and monitoring treatment and progression of $\mathrm{AD}$. Tau ${ }^{[99,100]}$, and phosphorylated Tau have been detected in exosomes isolated from $\mathrm{AD}$ patients ${ }^{[101]}$, and can potentially serve as biomarkers for early diagnosis of $\mathrm{AD}$, although further investigation is required to establish this connection. Furthermore, recent research has shown that serum-derived neuronal exosomes might be a potential biomarker for diagnosis and clinical monitoring of $\mathrm{AD}^{[102,103]}$. The use of exosomes as a delivery system for therapeutic drugs has also been extensively studied. Intranasal administration of exosome encapsulated drug led to rapid distribution of drugs into the brain ${ }^{[104]}$, indicating the possibility that exosomes can cross the blood brain barrier bidirectionally. Indeed, a large number of studies have shown that injection of exosomes as a drug delivery system could reduce $A \beta$ and other relevant pathological changes ${ }^{[97]}$.

\section{Role of exosome in Parkinson's disease}

Parkinson's disease (PD) is one of the most common neurodegenerative disorders affecting millions of people worldwide. The pathological hallmark of PD is the presence of Lewy bodies which contain misfolded $\alpha$-synuclein ( $\alpha$-syn) that tends to aggregate, resulting in progressive loss of dopaminergic neurons in 
substantia nigra and striatum ${ }^{[105]}$.

Studies showed that Lewy bodies are initially found in the peripheral tissues, and then gradually spread to the brain stem, and eventually to cerebral cortex, suggesting PD progressed into the central nervous system from peripheral tissues, similar to prion-like disease ${ }^{[106]}$. Interestingly, studies revealed that exosomes play a critical role in the propagating and progression of $\mathrm{PD}^{[107]}$. First, exosomes have been found to be a carrier that can deliver pathological proteins: both newly synthesized and aggregated forms of $\alpha$-syn could be released through unconventional, endoplasmic reticulum/Golgi-independent exocytosis. Intravesicular $\alpha-$ syn has a greater tendency to aggregate than the cytosolic protein. This secretion was enhanced by proteasomal and mitochondrial dysfunction associated with $\mathrm{PD}^{[108]}$. Further studies revealed that synaptic vesicles that contain $\alpha$-syn could be sorted into early endosomes through Golgi or clathrin-mediated endocytosis ${ }^{[109]}$, and then transported into MVBs and fused with membrane to secrete the exosomes ${ }^{[110]}$. Alternatively, $\alpha$-syn could also be sorted into the recycling endosome system and exocytosed as secretory granules ${ }^{[111]}$. Exosomes derived from $\alpha$-synuclein producing cells, are released in a calcium-dependent manner. Studies have also shown that exosomes contribute to the formation of aggregation of $\alpha$-syn: monitoring the aggregation kinetics with thioflavin $\mathrm{T}$ fluorescence revealed that exosomes facilitated the process by providing a catalytic environment for nucleation ${ }^{[112]}$. Quantification of cerebrospinal fluid (CSF) exosome numbers and $\alpha$-syn content from PD patients revealed a correlation with the severity of cognitive impairment. Interestingly, incubation of exosomes derived from CSF of patients with PD and Lewy body dementia induced oligomerization of soluble $\alpha$-synuclein in recipient cells in a dose-dependent manner. One hypothesis is that a pathogenic species of $\alpha$-syn in these exosomes could induce oligomerization of soluble $\alpha$-syn in the recipient cells to confer disease pathology ${ }^{[113]}$. It has also been suggested that exosomemediated release of toxic forms of oligomeric $\alpha$-syn, which is more easily taken up by recipient cells than free $\alpha$-syn may be a mechanism for clearing toxic $\alpha$-syn oligomers when autophagy is insufficient $t^{[14]}$.

Moreover, recent studies revealed that exosomes originated from the central nervous system could cross the blood brain barrier and carry the pathologic proteins into the blood ${ }^{[115]}$. Therefore, the cargo of serum/plasma-derived exosomes from patients with $\mathrm{PD}$ has been under extensive study as containing promising biomarkers in PD pathogenesis and clinical progression ${ }^{[116-119]}$.

It is noteworthy that exosomes are currently exploited as a drug delivery vehicle for treating PD. Several studies have demonstrated significant neuroprotective effects using exosome-based delivery system in in vitro and in vivo models of $\mathrm{PD}^{[120-122]}$. For example, intranasal administration of catalase-loaded exosomes effectively protected dopamine neurons in the substantia nigra pars compacta against oxidative stress in PD mouse brain ${ }^{[120]}$; and intravenous treatment with dopamine-loaded serum-derived exosomes also produced significant effects in PD mouse models ${ }^{[122]}$. However, the use of exosome delivery of therapeutics to treat PD remains challenging.

\section{Role of exosomes in Prion disease}

Prion disease is a fatal neurodegenerative disease in humans and animals, caused by infectious abnormal microscopic protein particles known as prions. Prion disease is primarily characterized by assemblies of misfolded beta-sheet prion proteins in the brain and a rapid decline in cognition and cerebral and cerebellar functions $s^{[123]}$. Although the mechanism of prion transmission still remains unclear, studies have shown that misfolded prion proteins are associated with exosomes, and these exosomes could spread the disease $\mathrm{e}^{[124]}$. Furthermore, studies showed that infection of N2a neuroblastoma cells with prions associated with scrapie could induce the release of prion proteins into the medium, predominantly via exosomes ${ }^{[125]}$. Knockdown of HRS/Vps27, a subunit of ESCRT-0 or TSG101-ESCRT-I subunit in Mov 127S cells significantly reduced 
accumulation or release of infective prion, suggesting that ESCRT-dependent and independent transmission mechanisms are both involved in the regulation of exosome-mediated release of prion proteins ${ }^{[126]}$. Stimulation of exosome release with monensin increased prion infectivity; by contrast, inhibition of exosome release with GW4869 decreased prion spreading ${ }^{[127]}$. Studies have also revealed that exosomes derived from neurons infected by prion could infect normal neurons and initiate prion propagation. In addition, these exosomes could induce prion disease when inoculated into mice. Interestingly, these prion proteins were found to have undergone $\mathrm{N}$-terminal modification and selection of specific glycoforms for incorporation into exosomes ${ }^{[128]}$. In line with these findings, it was also reported that exosomes derived from infected mice could spread prion disease ${ }^{[129]}$. Recent studies also revealed that some specific miRNAs such as miR-146a, miR-29b found within exosomes from prion-infected cells may play important roles at various stages of spreading of prion disease ${ }^{[130]}$. All the data support that exosome potentially contributes to the rapid colonization in the development of prion disease.

\section{Role of exosomes in amyotrophic lateral sclerosis}

Amyotrophic lateral sclerosis (ALS) is a fatal neurodegenerative disease in humans, which is characterized by progressive muscle atrophy due to the loss of motor neurons. Approximately $10 \%$ of ALS patients are familial, and the rest of $90 \%$ are sporadic. Both environment and genetic factors such as mutation of superoxide dismutase-1 (SOD1) and nuclear TAR DNA-binding protein 43 (TDP-43) have been shown to be involved in the pathogenesis of $\mathrm{ALS}^{[131]}$. A common pathologic feature of ALS is the aggregation of misfolded cytoplasmic proteins, for instance, TDP-43, ubiquilin 2 and SOD $1^{[132]}$. TDP-43 is an RNA/DNA binding protein that regulates RNA transcription and DNA repair. Hyperphosphorylated and ubiquitinated TDP-43 has been reported to contribute to the development of $\mathrm{ALS}^{[133]}$. Strikingly, recent studies have revealed that aggregated TDP-43 or SOD1 proteins could be transported by exosomes to recipient cells to induce neurotoxicity ${ }^{[134,135]}$. In clinical studies, TDP-43 levels have been reported to be much higher in exosomes derived from frozen post-mortem temporal cortices of patients with sporadic ALS, compared with controls ${ }^{[136]}$. A clinical 3- and 6-month follow up study also showed exosomal TDP-43 levels were much higher in ALS patients compared with the control group ${ }^{[137]}$. In vitro, TDP-43 is secreted via exosomes in Neuroza cells, and inhibition of exosome secretion exacerbates the aggregation of TDP-43. In addition, inhibition of exosome secretion also worsens the phenotype of TDP- $43^{\mathrm{A} 315 \mathrm{~T}}$ transgenic mice ${ }^{[136]}$. Other studies showed that exosome-induced cytokine secretion is compromised in CD14++ monocytes from ALS patients, and this abnormality is modulated by exosomal TDP-43, suggesting that exosomal TDP-43 contributes to the impaired neuroinflammatory reaction in ALS pathogenesis ${ }^{[134]}$.

With distinct advantages, exosomes can also be used as therapeutic delivery carriers. Exosomes isolated from adipose-derived stem cells have been shown to restore mitochondrial complex I activity, efficiency of electron transfer system and membrane potential in an in vitro model of ALS, NSC-34 cell line overexpressing human mutated SOD1, suggesting a potential therapy for ALS using such exosomes ${ }^{[138]}$.

\section{Role of exosomes in Huntington's disease}

Huntington's disease (HD) is a progressive autosomal dominant neurodegenerative disease that is characterized by cognitive impairment and involuntary choreiform movements. Pathologically, it is caused by CAG expansion in exon 1 in Huntingtin gene that leads to production of mutant huntingtin (mHtt). Emerging research has revealed that the mutated products, polyglutamine protein could lead to severe neuronal toxicity, and CAG repeat length is positively associated with clinical symptoms ${ }^{[139]}$. To date, studies have implied that exosomes are involved in the pathogenesis and propagation of Huntington disease ${ }^{[140]}$. When SH-SY5Y cells were cultured with conditioned medium from HEK cells that overexpress GFP, GFPmHtt-Q19 or GFP-mHtt-Q103, the exogenous mHtt proteins were detectable within SH-SY5Y cells after 5 days of exposure. In addition, after co-culturing mouse neural stem cells with exosomes derived from 
fibroblast from HD patient carrying the $143 \mathrm{CAG}$ repeat (HD143F) for 4 days, mHtt aggregates were detected within the neurons, suggesting $\mathrm{mHtt}$ could propagate from cell to cell through internalizing exosomes that contain pathological proteins. Furthermore, intraventricular injection of exosomes isolated from HD143F, resulted in the Huntington-like phenotype in mice, and $\mathrm{mHtt}$ was detected in the striatum $^{[141]}$. In another study, both in vivo and in vitro data suggest that extracellular vesicles can transfer toxic trinucleotide repeat RNAs between cells and trigger the manifestation of HD-related behaviors and pathology in mice; however, activity of exosomes or cell-type specificity was not fully evaluated ${ }^{[142]}$. These findings support the hypothesis that exosomes contribute to the HD progression by transferring toxic proteins or RNAs from one cell to another. Data have revealed that certain types of circulating microRNAs were up or down regulated in patients with HD, but exosome-derived microRNAs as biomarkers are still under investigation ${ }^{[143,144]}$. Moreover, recent studies showed that injection of exosome-delivered miR-124 into R6/2 transgenic HD mice reduced the RE-1 Silencing Transcription Factor, which is involved in the development of $\mathrm{HD}^{[145]}$. In addition, infusion of hydrophobically modified Htt-hsiRNA-loaded exosomes into mouse striatum resulted in significant bilateral silencing of about $35 \%$ of Huntingtin mRNA $^{[146]}$. Thus, the potential use of exosomes as a route for delivering various siRNAs to the brain to suppress expression of mHtt or other relevant regulatory proteins offers another approach to treating HD.

\section{Role of exosomes in epilepsy}

Epilepsy is a neurological disorder that is characterized by abnormal electrical discharge of brain neuron $s^{[147]}$. Status epilepticus can lead to neuron damage and gliosis ${ }^{[148]}$. Emerging studies have suggested that microvesicles such as exosomes could be released following brain injury or stimulation and serve as a biomarker for epilepsy. For example, status epilepticus induced by intra-amygdala kainic acid led to upregulation of both ESCRT-dependent and -independent signaling pathways and thus increased exosome release in mice. This effect lasted for a long time and the enhanced secretion of exosomes was still detectable 2 weeks after status epilepticus ${ }^{[149]}$. In addition, studies from both animals and human have implied that certain types of exosomal miRNA are highly associated with epilepsy. In a rat model of chronic temporal lobe epilepsy, miR-346 and miR-331-3p were found to be decreased in extracellular vesicles of the forebrain ${ }^{[150]}$. Besides, a clinical study involving 40 patients with mesial temporal lobe epilepsy with hippocampal sclerosis (mTLE-HS) showed that two exosomal miRNAs were upregulated, while 48 miRNAs were downregulated. Among these candidates, exosomal miRNA-8071 was reported to have the sensitivity of $83.33 \%$ and the specificity of $96.67 \%$ for diagnosis of mTLE-HS ${ }^{[151]}$. In another study, exosomal circulating miRNAs, such as miR194-2-5p, miR15a-5p, miR-132-3p, and miR-145-5p, have been reported to be potential biomarkers in patients with focal cortical dysplasia and refractory epilepsy ${ }^{[152]}$. Interestingly, intranasal administration of A1-exosomes derived from human bone marrow-derived MSCs rescued neuron loss, inflammation and neurogenesis, as well as alleviated compromised memory and cognitive capacity in mice which typically occur after status epilepticus ${ }^{[153]}$. These studies demonstrate that epilepsy could alter exosome release and its miRNA content, which could be a potential biomarker for clinical diagnosis. Further studies in exosomes will be needed to identify the distinct types of epilepsy subtype to determine the specific miRNA pathophysiological significance for epileptogenesis.

\section{Role of exosomes in multiple sclerosis}

Multiple sclerosis (MS) is a chronic inflammatory demyelinating disease of the central nervous system ${ }^{[154]}$. Currently, the etiology of MS remains elusive, and the diagnosis mainly relies on clinical symptoms. Thus, earlier diagnosis and effective clinical intervention are very important for improving patient outcomes. Recent studies have found that exosomal contents such as myelin oligodendrocyte glycoprotein ${ }^{[155]}$, sphingomyelinase (SMase) ${ }^{[156]}$, and a variety of microRNA ${ }^{[157-160]}$ are potential diagnostic biomarkers for MS. In addition, Schwann cell-derived exosomes contain a variety of neuroprotective proteins and antiinflammatory factors ${ }^{[161]}$ that play critical roles in MS via regulating myelin membrane biogenesis and 
providing trophic factors required for myelin maintenance ${ }^{[162]}$. For instance, exosomes which contain myelin and protective proteins against stress, were released from oligodendrocytes into the extracellular space in a calcium dependent manner ${ }^{[163]}$; Schwann cell-derived exosomes can improve axonal regeneration after axotomy ${ }^{[164]}$, and increase nerve activity ${ }^{[165]}$. Exosomes from adipose-derived mesenchymal stem cells, bone marrow-derived mesenchymal stem cells, and umbilical cord stem cells have shown potential therapeutic effects in protecting oligodendrocyte and promoting neurite outgrowth and nerve regeneration ${ }^{[166-168]}$.

\section{Function of exosomes in stroke}

Stroke has been increasing during past few decades and has become one of the major life-threatening medical conditions around the world. Thus, early diagnosis and effective monitoring of recovery phases are critical for the management of stroke patients. Compared with most biomarkers obtained from blood and body fluids, exosomes have an advantage due to their high heterogeneity ${ }^{[7]}$ which reflects the pathophysiological conditions of the cells from which they originate, and thus their cargo are potential biomarkers for diagnosis and clinical evaluation. Studies have shown that exosomes can cross the blood brain barrier and enter peripheral blood and cerebral spinal fluid after stroke ${ }^{[69]}$. In addition, exosomes orchestrate a complicated process after stroke involving nerve regeneration, angiogenesis, neurogenesis, remodeling of immune response, neuronal plasticity and axon dendrite outgrowth ${ }^{[170]}$. Studies have shown that endothelial cell-derived exosomes can promote the differentiation of neural progenitor cells into oligodendrocytes for myelination; neuron and neuronal progenitor cell-derived exosomes can regulate peripheral immune response; pericyte-derived exosomes can facilitate neurogenesis; circulating endothelial progenitor cell-derived exosomes can facilitate angiogenesis by interacting with cerebral endothelial cells ${ }^{[7]}$. Further studies revealed that mesenchymal stromal cell-derived exosome enhanced neurite branch and length in rat cultured neurons after middle artery occlusion ${ }^{[171]}$. Exosomal miR-126 and miR-124 were also reported to be involved in the angiogenesis ${ }^{[9,172]}$ in rats and neurogenesis in mice after stroke ${ }^{[173]}$. However, exosomes also produce some adverse effects in peripheral organs after stroke, such as increasing proinflammatory cytokines and activating $\mathrm{T}$ and $\mathrm{B}$ lymphocytes, thus effecting heart ${ }^{[174]}$ kidney $^{\left[{ }^{[175]} \text {, and }\right.}$ digestive intestine system ${ }^{[7]}$.

Extensive studies have shown that stroke could induce a variety of changes in the contents of exosomes released from central nervous system. For example, next generation sequencing analysis showed that human neural stem cell-derived miroRNAs were altered by hypoxic condition ${ }^{[176]}$. Data from both human and animal models suggested that certain types of exosomal cargoes were altered: In animal models, plasmaderived exosomal rno-miR-122-5p was significantly downregulated and rno-miR-300-3p upregulated in ischemic rats ${ }^{[177]}$. In clinical studies, proteome analysis of microvesicles from plasma of patients with lacunar infarction revealed that brain-related proteins such as myelin basic protein, focal adhesion and coagulation related proteins were upregulated, and albumin was downregulated in patients with adverse outcomes compared with matched controls ${ }^{[178]}$. Analysis of plasma EV from patients with manifest vascular disease showed elevated protein cystatin C and CD14 levels correlated with white matter lesions and progression of brain atrophy ${ }^{[179]}$. In patients with acute ischemic stroke, the serum exosome levels of miR-9 and miR-124 were both elevated compared with healthy controls, and positively correlated with National institute of Health Stroke Scale scores (NIHSS), infarct volumes and IL-6 levels ${ }^{[180]}$. Plasma-derived exosome miR-422a and miR-125b-2-3p were both decreased during the subacute phase of ischemic stroke, with miR-422a increased in the acute phase in comparison with controls ${ }^{[181]}$. In addition, exosomal miRNA such as miR223, miR-21-5p and miRNA-30a-5p were also reported to be highly related with occurrence and severity of stroke in several clinical studies ${ }^{[182,183]}$. These results suggest that designing a multiplex platform to assay for multiple biomarker molecules in exosomes known to be associated with stroke might be a promising approach for diagnosis and clinical progress evaluation of stroke patients, especially with the advancement 
of exosome isolation and purification techniques.

\section{Role of exosomes in traumatic brain injury}

Traumatic brain injury (TBI) often leads to injury-induced death and disability around the world ${ }^{[184]}$. After TBI, brain parenchymal damage and hemorrhage and compromised blood-brain barrier, as well as associated inflammation, oxidative stress and cell death contribute to the TBI-induced pathological alterations and dysfunction. As a critical player in cell communication, exosomes have been proposed to be able to carry specific biomarkers during traumatic brain injury and can serve in early diagnosis of concussion and monitoring of clinical progress ${ }^{[185]}$. Recent studies implied that certain components such as miR-124-3p in microglial exosomes were upregulated significantly after TBI and exerted anti-inflammatory function and promoted neurite outgrowth ${ }^{[186]}$. In another study in veterans with mild traumatic brain injury, elevated exosome-derived neurofilament light chain was observed, even years after injury ${ }^{[187]}$. Studies of serum-derived neuronal exosomes from patients with acute TBI and chronic TBI showed that proteins associated with neuronal functions were significantly increased in acute TBI, while neuropathological proteins were up-regulated in both acute and chronic TBI. These results suggest that cargo in serum-derived neuronal exosomes could act as potential biomarkers for clinical diagnosis ${ }^{[188]}$. Additionally, the capacity of exosomes to cross the blood-brain barrier offer a potentially effective therapeutic approach in treatment of patients with $\mathrm{TBI}^{[189]}$.

\section{Roles of exosomes in neuropsychiatric disorders}

Neuropsychiatric disorders such as major depression and schizophrenia are associated with certain changes of brain structures and neurotransmitters. Although the molecular mechanism is not fully understood, emerging studies suggest that miRNAs enriched in exosomes may be key factors in the development of neuropsychiatric disorders ${ }^{[190-194]}$. Acting as a complicated mediator of cell communications, alterations of exosomal components have been identified in patients with neuropsychiatric disorder ${ }^{[10]}$. One analysis of exosomal miRNAs from frozen postmortem prefrontal cortices of patients revealed that miR-497 was significantly elevated in schizophrenia, and miR-29c increased in bipolar disorders in comparison with control ${ }^{[195]}$. Genome-wide analysis of miRNAs from serum exosomes, with subsequent bioinformatic predictions and validations, has also indicated miRNA dysregulation in schizophrenic patients ${ }^{[196]}$. Of all the miRNAs, hsa-miR-206 was the most upregulated in these patients. Hsa-miR-206 has been reported to interact with BDNF mRNA directly, leading to the decreased expression of this gene and compromised cognitive function in mice ${ }^{[197]}$. In another study, in patients with depression, 12 miRNAs that regulate the neurotrophin pathway were found to be increased, and 20 miRNAs that control apoptosis, cell growth, immune and hypoxia activity were downregulated ${ }^{[198]}$. A recent study has revealed that exosomal miR-139$5 \mathrm{p}$ is significantly increased in patients with major depressive disorder in comparison with controls, suggesting it might be a potential biomarker for this disorder ${ }^{[199]}$.

To date, studies in the role of exosomes in neuropsychiatric disorders are very limited. These findings have opened up challenging possibilities of uncovering the function of exosomes and molecules associated with them in mental disorders.

\section{Exosomes in brain tumors}

Glioblastoma multiforme (GBM) is the most aggressive and common primary tumor of the adult brain, with median survival of less than 15 months from diagnosis ${ }^{[200]}$. Regardless of patients receiving rigorous standard of care, such as surgical resection alongside chemotherapy and/or radiotherapy, this rare astrocytoma has very poor prognosis ${ }^{[201,202]}$. Among the heterogenous cell populations that form the GBM tumor mass are the cancer stem cells, which contribute to therapy resistance, tumor growth and recurrence $^{[203-206]}$. Recent reports have ${ }^{[207]}$ suggested that EVs including exosomes mediate critical bilateral 
communication between the tumor cells and their microenvironment to sustain the growth of malignant GBM. A longitudinal time-lapse imaging study showed that glioma cells have crosstalk with non-glioma cells such as glial cells, neurons and vascular cells through EVs, to alter the tumor microenvironment and promote glioma growth in vivo ${ }^{[208]}$. GBM derived EVs are known to facilitate angiogenesis, tumor progression and invasion, drug resistance and immune regulation ${ }^{[209-212]}$ [Figure 3]. Moreover, various GBM exosomal cargoes are involved in mediating these processes [Table 2].

Hypoxia within the GBM microenvironment promotes neo-angiogenesis, as a means to supply oxygen and nutrients to the rapidly growing tumor cells. VEGF-A carrying EVs secreted by glioma stem cells (GSC), stimulates endothelial cells to proliferate, migrate and form tubular structures, promoting vasculature ${ }^{[213]}$. In addition, GSC exosomes can transfer miRNAs such as miR-21 and miR-26a to endothelial cells, to upregulate VEGF expression and support GBM angiogenesis ${ }^{[21,215]}$. Studies using clinical samples have shown that microvesicles derived from CSF of GBM patients upregulate proliferation of cultured endothelial cells through AKT/beta-catenin pathway ${ }^{[216]}$. Oncogenic EGFRvIII and tissue transglutaminase are reportedly other protein factors transferred through EVs, which are known to induce mitogenic and/or angiogenic signaling in recipient cells $^{[217,218]}$. Interestingly, exosome-mediated delivery of long non-coding RNAs such as $\operatorname{lncCCAT}-2$ and $\ln \mathrm{PPOU} 3 \mathrm{~F} 3$ can also enhance vascularization of $\mathrm{GBM}^{[219,220]}$. On the contrary, miR-1 enriched glioma EVs have been implicated in suppressing angiogenesis and tumor growth ${ }^{[221]}$. Increased growth and aggressiveness of advanced stages of GBM is associated with the phenotypic transition from proneural to mesenchymal subtype. GSC EVs contribute towards this process, by way of transferring mRNAs, miRNAs and other regulatory RNAs, and transcription factors, which can possibly reprogram the recipient cells, alter their epigenetic signatures and render the GBM microenvironment more permissive to malignant transformation ${ }^{[21,222,223]}$. EV-mediated crosstalk in GBM involves the interaction between a chemokine receptor CCR8 on recipient cells and the glycans on the EV surface, with the CCL1 ligand acting as a bridging molecule ${ }^{[224]}$. RNA-seq and DNA methylation analyses showed that proangiogenic miRNA such as miR-9-5p transferred via GSC EVs can reprogram human brain endothelial cells in vitro to induce angiogenesis, by distinct pathways compared to those activated by vascular growth factors $^{[225]}$. Similar molecular profiling studies conducted earlier using GSC EVs had revealed that the molecular subtypes and functional state of GSCs determine the tumor regulatory effect of $\mathrm{EVs}^{[226,227]}$.

GBM cells interact with the surrounding astrocytes to modulate tumor growth and survival. In a study using patient tumor derived cell lines, it was shown that GBM EVs can transform normal human astrocytes to a pro-tumorigenic phenotype, exhibiting increased production of growth factors, chemokines and cytokines, to support in vitro growth of GBM cells ${ }^{[207]}$. GBM EVs regulate tumor signaling pathways such as p53 and cMYC in astrocytes to induce a senescence associated secretory phenotype, to favor tumor progression ${ }^{[228]}$. Moreover, EVs derived from GBM cells were shown to induce podosome formation, ECM degradation and increased migration of astrocytes ${ }^{[207,228]}$. Astrocytes cultured with GBM EVs show enhanced secretion of immunosuppressive cytokines such as CSF2 and interleukins 4, 10 and 13, thus providing a tumor supportive microenvironment. EVs secreted by irradiated GBM cells have enhanced presence of CD147, which in turn stimulates increased MMP9 release from recipient astrocytes, suggesting the contribution of astrocyte signaling in promoting GBM invasiveness, particularly in response to ionizing radiation ${ }^{[229]}$. A recent study reported that GSC EVs induce metabolic reprogramming of pre-transformed astrocytes to enhance proliferation, self-renewal and tumor growth in a mouse allograft model ${ }^{[230]}$.

Immune suppression fosters aggressive transformation of brain tumor. The molecular cargo transferred by GBM EVs can influence the status of tumor-associated macrophages or myeloid cells (TAMs) ${ }^{[231]}$. GBM EVs induce the in vitro differentiation of peripheral blood derived monocytes to anti-inflammatory M2- 
Table 2. Function of EVs/exosomes in regulating glioma

\begin{tabular}{|c|c|c|c|c|}
\hline Types of exosomal cargo & Parental cell & $\begin{array}{l}\text { Recipient } \\
\text { cell }\end{array}$ & Function & Ref. \\
\hline VEGF-A & GSC & Endothelial cell & Promote angiogenesis & Treps et al. ${ }^{[213]}, 2017$ \\
\hline miR-21, miR-26a, miR-9-5p & GSC & Endothelial cell & Promote angiogenesis & $\begin{array}{l}\text { Sun et al. }{ }^{[214]}{ }^{[215]} 2017 \\
\text { Wang et al. }{ }^{215]} 2019 \\
\text { Lucero et al. }{ }^{\left[225^{\prime}\right]}, 2020\end{array}$ \\
\hline IncCCAT-2, IncPOU3F3 & GBM cell & Endothelial cell & Promote angiogenesis & $\begin{array}{l}\text { Lang et al. }{ }^{[219]} 2017 \\
\text { Lang et al. }{ }^{[220]}, 2017\end{array}$ \\
\hline $\begin{array}{l}\text { EGFRvIII, tissue } \\
\text { transglutaminase }\end{array}$ & GBM cell & GBM cell & Support tumor growth & $\begin{array}{l}\text { Al-Nedawi et al. }{ }^{[217]}, 2008 \\
\text { Antonyak et al. }{ }^{[218]}, 2011\end{array}$ \\
\hline CD147 & Irradiated GBM cells & Astrocytes & Support tumor invasion & Colangelo et al. ${ }^{[229]}, 2020$ \\
\hline STAT3 proteins & GSC & Monocytes & Immunosuppression & $\begin{array}{l}\text { Gabrusiewicz et al. }{ }^{[235]} \\
\text {,2018 } \\
\text { Grimaldi et al. }{ }^{[236]} 2019 \\
\text { Ricklefs et al. }{ }^{[237]}, 2018\end{array}$ \\
\hline miR-21 & GBM cells & Microglia & $\begin{array}{l}\text { Immunosuppression, tumor } \\
\text { growth }\end{array}$ & $\begin{array}{l}\text { Abels et al. }{ }^{[234]}, 2019 \\
\text { Van der Vos et al. }{ }^{[231]}, 2016\end{array}$ \\
\hline$M G M T, A P N G$ & GBM cells & GBM cells & Chemoresistance & Shao et al. ${ }^{[210]}, 2015$ \\
\hline miR-9 & GBM cells & GBM cells & Chemoresistance & $\begin{array}{l}\text { Munoz et al. }{ }^{[239]}, 2013 \\
\text { Munoz et al. }{ }^{[238]^{\prime}}, 2015\end{array}$ \\
\hline miR-21 & $\begin{array}{l}\text { Tumor associated } \\
\text { macrophages }\end{array}$ & GBM cells & Chemoresistance & Chuang et al. ${ }^{[240]}, 2019$ \\
\hline
\end{tabular}

macrophages, which exhibit enhanced phagocytosis and secretion of IL-6 and VEGF, to support immune evasion of glioma ${ }^{[232]}$. Peripheral blood analyses of GBM patients signified the role of tumor-derived exosomes in promoting an immune evasive Th2 bias, and their ability to induce CD163 (a macrophage marker) expression on normal astrocytes ${ }^{[233]}$. EVs carrying miR-21 released by GBM cells were shown to target the expression of Btg2, an anti-proliferative protein in recipient microglia, subsequently reprogramming these cells to support tumor progression ${ }^{[23,234]}$. STAT3 pathway proteins present within GSC EVs including exosomes, also mediate immune suppressive changes of monocytes including their phenotype change to M2-macrophages, cytoskeletal reorganization, and upregulation of PD-L1 ligand, which binds to PD1 to inhibit T-Cell activation ${ }^{[235-237]}$.

Studies addressing the mechanism of resistance to Temozolomide (TMZ), an alkylating agent used as the standard of care for glioma, have uncovered the possible influence of EVs in the process. Using a microfluidic chip-based analysis, it was found that sera-derived EVs from GBM patients (small cohort study) are enriched in mRNA levels of MGMT (O6-methylguanine DNA methyltransferase) and APNG (alkylpurine-DNA-N-glycosylase), primary DNA repair enzymes involved in inducing chemoresistance ${ }^{[210]}$. miR-9 is upregulated in exosomes released from TMZ resistant glioma cell lines and is implicated in increasing MDR1 (multidrug resistance mutation 1) expression and repressing Patched (PTCH1), Sonic Hedgehog receptor to confer chemoresistance ${ }^{[238]}$. Transfer of anti-miR-9 through MSC exosomes to GBM cells was shown to impart chemosensitivity and reverse multidrug transporter expression ${ }^{[239]}$. Analysis of clinical samples has revealed that Pacritinib, a STAT3 inhibitor can potentially overcome TMZ resistance by reducing miR-21 enriched exosomes secreted by GBM-associated macrophages ${ }^{[240]}$.

EV cargo can be potential biomarkers for GBM diagnosis and progression. EGFRvIII is found in high levels within GBM EVs, and hence can be used as a potential biomarker ${ }^{[211]}$. A study conducted using clinical samples from GBM patients undergoing tumor resection, reported that CSF derived EVs can be developed as a diagnostic tool to assess EGFRvIII positive GBM status accurately ${ }^{[241]}$. CSF EVs of GBM patients have also been found to be enriched in miR-21 compared to non-oncologic patients, suggesting the potential use 


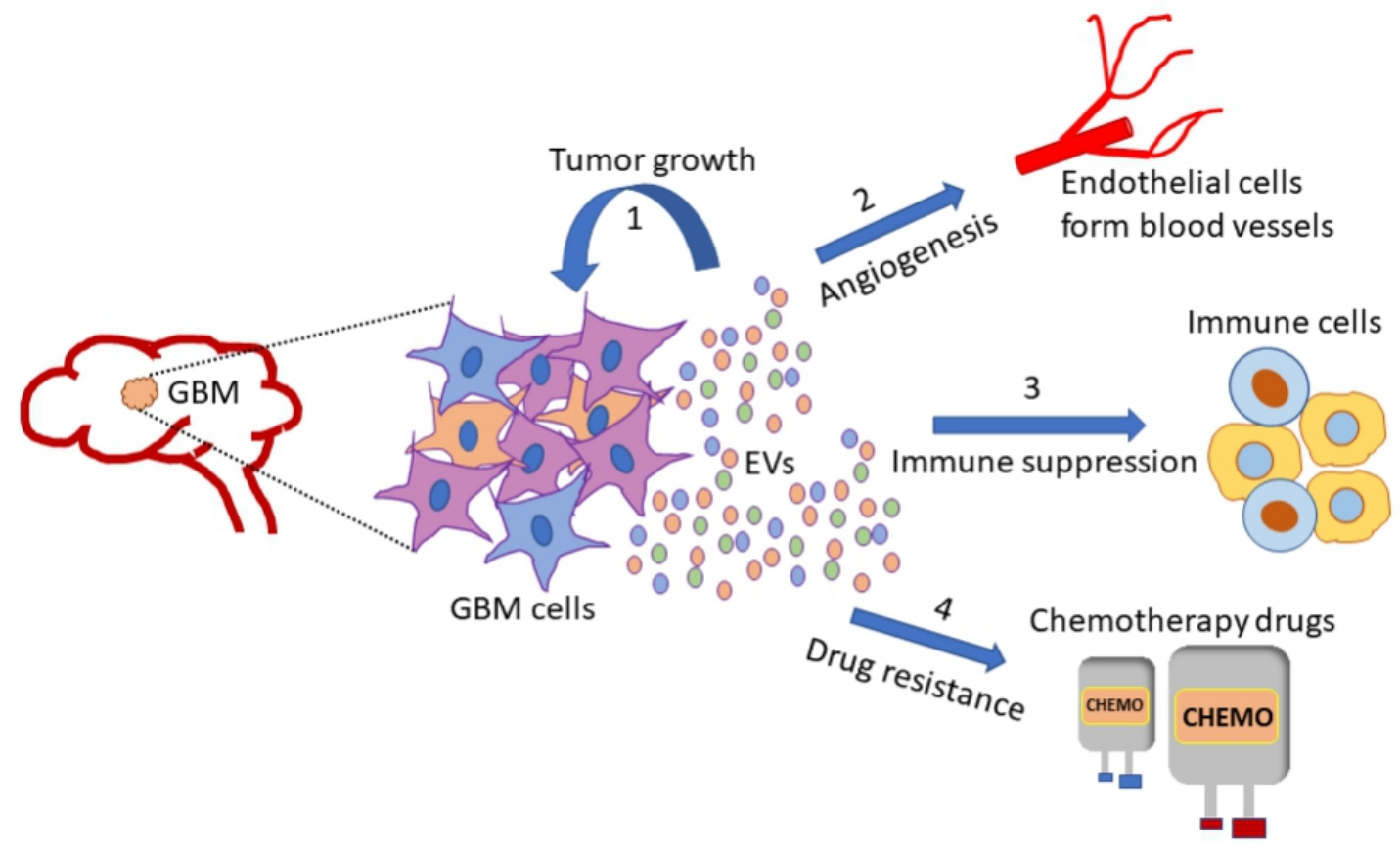

Figure 3. Glioblastoma multiforme (GBM) is one of the most aggressive tumors of the adult brain. Cells that make up the GBM tumor, release extracellular vesicles (EVs), which mediate the transfer of vital cues between tumor cells and the surrounding microenvironment. GBM tumor mass is highly heterogenous comprising differentiated tumor cells and glioma stem cells (GSCs). GSC derived EVs are particularly important players in sustaining glioma growth and invasion. Depending on their cell of origin, GBM EVs deliver unique cargo such as proteins, nucleic acids and lipids to recipient cells, to possibly alter their gene expression profile and phenotypes, and in the process favor malignant transformation. Some critical functions attributed to GBM EVs include (1) supporting tumor growth and survival; (2) promoting angiogenesis by regulating gene expression in endothelial cells; (3) mediating immune evasive phenotype changes in tumor associated immune cells: T cells, macrophages and microglia; (4) inducing resistance to chemotherapy drugs/ radiation therapy. GBM: Glioblastoma multiforme; EVs: extracellular vesicles.

of CSF derived EV miR-21 as another biomarker for GBM prognosis ${ }^{[242,243]}$. In addition, RNA/proteins with growth promoting functions such as TrkB (neurotrophin tyrosine kinase receptor-1), Timp1 (NF-kB target gene) and CLIC1 (circulatory protein), and PTEN, a tumor suppressor protein, enriched within EVs are some other potential prognostic biomarkers for $\mathrm{GBM}^{[200]}$.

\section{CONCLUSION AND PERSPECTIVES}

Emerging research in the last decade suggests that exosomes and EVs are critical players in regulating physiological and pathological processes in the brain. Exosomes and EVs mediate intercellular communication by trafficking of biomolecules such as proteins, lipid, mRNA, and miRNA.

Circulating exosomes have vast potential in being developed as a source of biomarkers for various neurodegenerative disorders and brain tumors, and as vehicles for drug delivery. Neurotoxic proteins associated with $\mathrm{AD}, \mathrm{PD}$ and prion disease, such as $\mathrm{A} \beta$, Tau, $\alpha$-synuclein and PrP respectively are encapsulated and transferred through exosomes. Oncogenic proteins (EGFRVIII, TrkB, Timp1) and miRNAs (miR-21, miR-9) carried as exosomal cargo can reprogram recipient cells in the tumor microenvironment to favor glioma progression. Besides targeting these exosomal proteins for therapeutics, the possibility of isolating exosomes readily from the circulating biofluids represents a novel and effective tool for non-invasive diagnosis and monitoring the status of various neurological conditions and glioma 
progression.

Knowledge of the fundamental aspects of exosome biology (exosome biogenesis, origin, cargo sorting and targeting to specific recipient cells) and the downstream signal transduction, is key to the application of exosomes for treatment of brain disorders. Although data have indicated that various exosomal proteins or miRNAs are altered during the development of neurodegenerative or other CNS diseases, precise signaling cascade or involvement is not well understood. This might be due to the limitation of isolation and characterization techniques of exosomes that fail to specifically capture and identify exosomes from specific cell type of origin, such as neurons or microglia from limited sample volume. Therefore, more specific exosome associated biomarkers and better isolation and purification techniques for capturing specific subpopulations of exosomes will greatly advance the ability to identify biomarkers.

Research advances in areas of exosome isolation, characterization, tissue targeting and understanding of their specific biological functions would allow exosomes to impact clinical therapy of neurological diseases. Indeed, the future prospect of developing the use of exosomes for delivery of functional cargo such as miRNA, siRNA and mRNA/proteins into the brain and other regions of the nervous system, such as in axonal regeneration, opens up exciting new avenues for drug delivery applications.

\section{DECLARATIONS}

\section{Authors' contributions}

Wrote and edited the manuscript: Xiao L, Hareendran S, Loh YP

\section{Availability of data and materials}

Not applicable.

\section{Financial support and sponsorship}

This research was supported by the Intramural Research Program of The Eunice Kennedy Shriver National Institute of Child Health and Human Development (NICHD) (ZIA HDo00056), National Institutes of Health, USA.

\section{Conflicts of interest}

The authors declare no conflict of interest.

\section{Ethical approval and consent to participate}

Not applicable.

\section{Consent for publication}

Not applicable.

\section{Copyright}

(C) The Author(s) 2021.

\section{REFERENCES}

1. Wolf P. The nature and significance of platelet products in human plasma. Br J Haematol 1967;13:269-88. DOI PubMed

2. Zhang Y, Liu Y, Liu H, Tang WH. Exosomes: biogenesis, biologic function and clinical potential. Cell Biosci 2019;9:19. DOI PubMed PMC

3. Cufaro MC, Pieragostino D, Lanuti P, et al. Extracellular Vesicles and Their Potential Use in Monitoring Cancer Progression and Therapy: The Contribution of Proteomics. J Oncol 2019;2019:1639854. DOI PubMed PMC

4. Théry C, Witwer KW, Aikawa E, et al. Minimal information for studies of extracellular vesicles 2018 (MISEV2018): a position statement of the International Society for Extracellular Vesicles and update of the MISEV2014 guidelines. J Extracell Vesicles 2018;7:1535750. DOI PubMed PMC 
5. Trams EG, Lauter CJ, Norman Salem J, Heine U. Exfoliation of membrane ecto-enzymes in the form of micro-vesicles. Biochim Biophys Acta 1981;645:63-70. DOI PubMed

6. Johnstone RM, Adam M, Hammond JR, Orr L, Turbide C. Vesicle formation during reticulocyte maturation. Association of plasma membrane activities with released vesicles (exosomes). J Biol Chem 1987;262:9412-20. PubMed

7. Liu W, Bai X, Zhang A, Huang J, Xu S, Zhang J. Role of Exosomes in Central Nervous System Diseases. Front Mol Neurosci 2019;12:240. DOI PubMed PMC

8. Malm T, Loppi S, Kanninen KM. Exosomes in Alzheimer's disease. Neurochem Int 2016;97:193-9. DOI PubMed

9. Osier N, Motamedi V, Edwards K, et al. Exosomes in Acquired Neurological Disorders: New Insights into Pathophysiology and Treatment. Mol Neurobiol 2018;55:9280-93. DOI PubMed

10. Saeedi S, Israel S, Nagy C, Turecki G. The emerging role of exosomes in mental disorders. Transl Psychiatry 2019;9:122. DOI PubMed PMC

11. Looze C, Yui D, Leung L, et al. Proteomic profiling of human plasma exosomes identifies PPARgamma as an exosome-associated protein. Biochem Biophys Res Commun 2009;378:433-8. DOI PubMed PMC

12. Street JM, Barran PE, Mackay CL, et al. Identification and proteomic profiling of exosomes in human cerebrospinal fluid. J Transl Med 2012;10:5. DOI PubMed PMC

13. Michael A, Bajracharya SD, Yuen PS, et al. Exosomes from human saliva as a source of microRNA biomarkers. Oral Dis 2010;16:34-8. DOI PubMed PMC

14. Gonzales PA, Pisitkun T, Hoffert JD, et al. Large-scale proteomics and phosphoproteomics of urinary exosomes. J Am Soc Nephrol 2009;20:363-79. DOI PubMed PMC

15. Admyre C, Johansson SM, Qazi KR, et al. Exosomes with immune modulatory features are present in human breast milk. J Immunol 2007;179:1969-78. DOI PubMed

16. Cañas JA, Sastre B, Rodrigo-Muñoz JM, Del Pozo V. Exosomes: A new approach to asthma pathology. Clin Chim Acta 2019;495:139-47. DOI PubMed

17. Zhang X, Yuan X, Shi H, Wu L, Qian H, Xu W. Exosomes in cancer: small particle, big player. J Hematol Oncol 2015;8:83. DOI PubMed PMC

18. Huang X, Yuan T, Tschannen M, et al. Characterization of human plasma-derived exosomal RNAs by deep sequencing. BMC Genomics 2013;14:319. DOI PubMed PMC

19. Hewson C, Capraro D, Burdach J, Whitaker N, Morris KV. Extracellular vesicle associated long non-coding RNAs functionally enhance cell viability. Noncoding RNA Res 2016;1:3-11. DOI PubMed PMC

20. Soria FN, Pampliega O, Bourdenx M, Meissner WG, Bezard E, Dehay B. Exosomes, an Unmasked Culprit in Neurodegenerative Diseases. Front Neurosci 2017;11:26. DOI PubMed PMC

21. Sahu R, Kaushik S, Clement CC, et al. Microautophagy of cytosolic proteins by late endosomes. Dev Cell 2011;20:131-9. DOI PubMed PMC

22. Record M. Intercellular communication by exosomes in placenta: a possible role in cell fusion? Placenta 2014;35:297-302. DOI PubMed

23. Hessvik NP, Llorente A. Current knowledge on exosome biogenesis and release. Cell Mol Life Sci 2018;75:193-208. DOI PubMed PMC

24. Colombo M, Moita C, van Niel G, et al. Analysis of ESCRT functions in exosome biogenesis, composition and secretion highlights the heterogeneity of extracellular vesicles. J Cell Sci 2013;126:5553-65. DOI PubMed

25. Henne WM, Buchkovich NJ, Emr SD. The ESCRT pathway. Dev Cell 2011;21:77-91. DOI PubMed

26. Baietti MF, Zhang Z, Mortier E, et al. Syndecan-syntenin-ALIX regulates the biogenesis of exosomes. Nat Cell Biol 2012;14:677-85. DOI PubMed

27. Hurley JH. ESCRTs are everywhere. EMBO J 2015;34:2398-407. DOI PubMed PMC

28. Stuffers S, Sem Wegner C, Stenmark H, Brech A. Multivesicular endosome biogenesis in the absence of ESCRTs. Traffic 2009;10:925-37. DOI PubMed

29. Escola JM, Kleijmeer MJ, Stoorvogel W, Griffith JM, Yoshie O, Geuze HJ. Selective enrichment of tetraspan proteins on the internal vesicles of multivesicular endosomes and on exosomes secreted by human B-lymphocytes. J Biol Chem 1998;273:20121-7. DOI PubMed

30. Chairoungdua A, Smith DL, Pochard P, Hull M, Caplan MJ. Exosome release of $\beta$-catenin: a novel mechanism that antagonizes Wnt signaling. J Cell Biol 2010;190:1079-91. DOI PubMed PMC

31. Nazarenko I, Rana S, Baumann A, et al. Cell surface tetraspanin Tspan8 contributes to molecular pathways of exosome-induced endothelial cell activation. Cancer Res 2010;70:1668-78. DOI PubMed

32. Hurwitz SN, Conlon MM, Rider MA, Brownstein NC, Meckes DG Jr. Nanoparticle analysis sheds budding insights into genetic drivers of extracellular vesicle biogenesis. J Extracell Vesicles 2016;5:31295. DOI PubMed PMC

33. den Boorn JG, Dassler J, Coch C, Schlee M, Hartmann G. Exosomes as nucleic acid nanocarriers. Adv Drug Deliv Rev 2013;65:3315. DOI PubMed

34. Castro BM, Prieto M, Silva LC. Ceramide: a simple sphingolipid with unique biophysical properties. Prog Lipid Res 2014;54:53-67. DOI PubMed

35. Ostrowski M, Carmo NB, Krumeich S, et al. Rab27a and Rab27b control different steps of the exosome secretion pathway. Nat Cell Biol 2010;12:19-30; sup pp 1. DOI PubMed

36. Hsu C, Morohashi Y, Yoshimura S, et al. Regulation of exosome secretion by Rab35 and its GTPase-activating proteins TBC1D10A- 


\section{J Cell Biol 2010;189:223-32. DOI PubMed PMC}

37. Savina A, Furlán M, Vidal M, Colombo MI. Exosome release is regulated by a calcium-dependent mechanism in K562 cells. J Biol Chem 2003;278:20083-90. DOI PubMed

38. Parolini I, Federici C, Raggi C, et al. Microenvironmental pH is a key factor for exosome traffic in tumor cells. J Biol Chem 2009;284:34211-22. DOI PubMed PMC

39. Lehmann BD, Paine MS, Brooks AM, et al. Senescence-associated exosome release from human prostate cancer cells. Cancer Res 2008;68:7864-71. DOI PubMed PMC

40. Beer L, Zimmermann M, Mitterbauer A, et al. Analysis of the Secretome of Apoptotic Peripheral Blood Mononuclear Cells: Impact of Released Proteins and Exosomes for Tissue Regeneration. Sci Rep 2015;5:16662. DOI PubMed PMC

41. Xiao X, Yu S, Li S, et al. Exosomes: decreased sensitivity of lung cancer A549 cells to cisplatin. PLoS One 2014;9:e89534. DOI PubMed PMC

42. King HW, Michael MZ, Gleadle JM. Hypoxic enhancement of exosome release by breast cancer cells. BMC Cancer 2012;12:421. DOI PubMed PMC

43. Kanemoto S, Nitani R, Murakami T, et al. Multivesicular body formation enhancement and exosome release during endoplasmic reticulum stress. Biochem Biophys Res Commun 2016;480:166-72. DOI PubMed

44. Miyanishi M, Tada K, Koike M, Uchiyama Y, Kitamura T, Nagata S. Identification of Tim4 as a phosphatidylserine receptor. Nature 2007;450:435-9. DOI PubMed

45. Segura E, Nicco C, Lombard B, et al. ICAM-1 on exosomes from mature dendritic cells is critical for efficient naive T-cell priming. Blood 2005;106:216-23. DOI PubMed

46. Feng D, Zhao WL, Ye YY, et al. Cellular internalization of exosomes occurs through phagocytosis. Traffic 2010;11:675-87. DOI PubMed

47. Fitzner D, Schnaars M, van Rossum D, et al. Selective transfer of exosomes from oligodendrocytes to microglia by macropinocytosis. J Cell Sci 2011;124:447-58. DOI PubMed

48. Frühbeis C, Fröhlich D, Krämer-Albers EM. Emerging roles of exosomes in neuron-glia communication. Front Physiol 2012;3:119. DOI PubMed PMC

49. Guitart K, Loers G, Buck F, Bork U, Schachner M, Kleene R. Improvement of neuronal cell survival by astrocyte-derived exosomes under hypoxic and ischemic conditions depends on prion protein. Glia 2016;64:896-910. DOI PubMed

50. Chivet M, Javalet C, Laulagnier K, Blot B, Hemming FJ, Sadoul R. Exosomes secreted by cortical neurons upon glutamatergic synapse activation specifically interact with neurons. J Extracell Vesicles 2014;3:24722. DOI PubMed PMC

51. Gurunathan S, Kang MH, Jeyaraj M, Qasim M, Kim JH. Review of the Isolation, Characterization, Biological Function, and Multifarious Therapeutic Approaches of Exosomes. Cells 2019;8:307. DOI PubMed PMC

52. Camussi G, Deregibus MC, Bruno S, Cantaluppi V, Biancone L. Exosomes/microvesicles as a mechanism of cell-to-cell communication. Kidney Int 2010;78:838-48. DOI PubMed

53. Gurunathan S, Kang MH, Kim JH. A Comprehensive Review on Factors Influences Biogenesis, Functions, Therapeutic and Clinical Implications of Exosomes. Int J Nanomedicine 2021;16:1281-312. DOI PubMed PMC

54. Lachenal G, Pernet-Gallay K, Chivet M, et al. Release of exosomes from differentiated neurons and its regulation by synaptic glutamatergic activity. Mol Cell Neurosci 2011;46:409-18. DOI PubMed

55. Bakhti M, Winter C, Simons M. Inhibition of myelin membrane sheath formation by oligodendrocyte-derived exosome-like vesicles. J Biol Chem 2011;286:787-96. DOI PubMed PMC

56. Edgar JM, Nave KA. The role of CNS glia in preserving axon function. Curr Opin Neurobiol 2009; 19:498-504. DOI PubMed

57. Tytell M, Greenberg S, Lasek R. Heat shock-like protein is transferred from glia to axon. Brain Research 1986;363:161-4. DOI PubMed

58. Tytell M. Release of heat shock proteins (Hsps) and the effects of extracellular Hsps on neural cells and tissues. Int J Hyperthermia 2005;21:445-55. DOI PubMed

59. Fauré J, Lachenal G, Court M, et al. Exosomes are released by cultured cortical neurones. Mol Cell Neurosci 2006;31:642-8. DOI PubMed

60. Ghidoni R, Paterlini A, Albertini V, et al. Cystatin C is released in association with exosomes: a new tool of neuronal communication which is unbalanced in Alzheimer's disease. Neurobiol Aging 2011;32:1435-42. DOI PubMed PMC

61. Korkut C, Li Y, Koles K, et al. Regulation of postsynaptic retrograde signaling by presynaptic exosome release. Neuron 2013;77:1039-46. DOI PubMed PMC

62. Bahrini I, Song JH, Diez D, Hanayama R. Neuronal exosomes facilitate synaptic pruning by up-regulating complement factors in microglia. Sci Rep 2015;5:7989. DOI PubMed PMC

63. Morel L, Regan M, Higashimori H, et al. Neuronal exosomal miRNA-dependent translational regulation of astroglial glutamate transporter GLT1. J Biol Chem 2013;288:7105-16. DOI PubMed PMC

64. Wang S, Cesca F, Loers G, et al. Synapsin I is an oligomannose-carrying glycoprotein, acts as an oligomannose-binding lectin, and promotes neurite outgrowth and neuronal survival when released via glia-derived exosomes. J Neurosci 2011;31:7275-90. DOI PubMed PMC

65. Prada I, Gabrielli M, Turola E, et al. Glia-to-neuron transfer of miRNAs via extracellular vesicles: a new mechanism underlying inflammation-induced synaptic alterations. Acta Neuropathol 2018;135:529-50. DOI PubMed PMC

66. Yamada J, Jinno S. Promotion of synaptogenesis and neural circuit development by exosomes. Ann Transl Med 2019;7:S323. DOI PubMed PMC 
67. Feliciano DM, Zhang S, Nasrallah CM, Lisgo SN, Bordey A. Embryonic cerebrospinal fluid nanovesicles carry evolutionarily conserved molecules and promote neural stem cell amplification. PLoS One 2014;9:e88810. DOI PubMed PMC

68. Bátiz LF, Castro MA, Burgos PV, et al. Exosomes as Novel Regulators of Adult Neurogenic Niches. Front Cell Neurosci 2015;9:501. DOI PubMed PMC

69. Ma Y, Li C, Huang Y, Wang Y, Xia X, Zheng JC. Exosomes released from neural progenitor cells and induced neural progenitor cells regulate neurogenesis through miR-21a. Cell Commun Signal 2019;17:96. DOI PubMed PMC

70. Sharma P, Mesci P, Carromeu C, et al. Exosomes regulate neurogenesis and circuit assembly. Proc Natl Acad Sci U S A 2019;116:16086-94. DOI PubMed PMC

71. Perets N, Oron O, Herman S, Elliott E, Offen D. Exosomes derived from mesenchymal stem cells improved core symptoms of genetically modified mouse model of autism Shank3B. Mol Autism 2020;11:65. DOI PubMed PMC

72. Elsharkasy OM, Nordin JZ, Hagey DW, et al. Extracellular vesicles as drug delivery systems: Why and how? Adv Drug Deliv Rev 2020;159:332-43. DOI PubMed

73. Gee P, Lung MSY, Okuzaki Y, et al. Extracellular nanovesicles for packaging of CRISPR-Cas9 protein and sgRNA to induce therapeutic exon skipping. Nat Commun 2020;11:1334. DOI PubMed PMC

74. Hebert LE, Weuve J, Scherr PA, Evans DA. Alzheimer disease in the United States (2010-2050) estimated using the 2010 census. Neurology 2013;80:1778-83. DOI PubMed PMC

75. Alzheimer's disease facts and figures. Alzheimers Dement;2020:391-460. DOI PubMed

76. Reza-Zaldivar EE, Hernández-Sapiéns MA, Minjarez B, Gutiérrez-Mercado YK, Márquez-Aguirre AL, Canales-Aguirre AA. Potential Effects of MSC-Derived Exosomes in Neuroplasticity in Alzheimer's Disease. Front Cell Neurosci 2018;12:317. DOI PubMed PMC

77. Xiao T, Zhang W, Jiao B, Pan CZ, Liu X, Shen L. The role of exosomes in the pathogenesis of Alzheimer' disease. Transl Neurodegener 2017;6:3. DOI PubMed PMC

78. DeLeo AM, Ikezu T. Extracellular Vesicle Biology in Alzheimer's Disease and Related Tauopathy. J Neuroimmune Pharmacol 2018;13:292-308. DOI PubMed PMC

79. Pérez M, Avila J, Hernández F. Propagation of Tau via Extracellular Vesicles. Front Neurosci 2019;13:698. DOI PubMed PMC

80. Podvin S, Jones A, Liu Q, et al. Dysregulation of Exosome Cargo by Mutant Tau Expressed in Human-induced Pluripotent Stem Cell (iPSC) Neurons Revealed by Proteomics Analyses. Mol Cell Proteomics 2020;19:1017-34. DOI PubMed PMC

81. Yuyama K, Sun H, Mitsutake S, Igarashi Y. Sphingolipid-modulated exosome secretion promotes clearance of amyloid- $\beta$ by microglia. J Biol Chem 2012;287:10977-89. DOI PubMed PMC

82. Yuyama K, Sun H, Sakai S, et al. Decreased amyloid- $\beta$ pathologies by intracerebral loading of glycosphingolipid-enriched exosomes in Alzheimer model mice. J Biol Chem 2014;289:24488-98. DOI PubMed PMC

83. An K, Klyubin I, Kim Y, et al. Exosomes neutralize synaptic-plasticity-disrupting activity of A $\beta$ assemblies in vivo. Mol Brain 2013;6:47. DOI PubMed PMC

84. Falker C, Hartmann A, Guett I, et al. Exosomal cellular prion protein drives fibrillization of amyloid beta and counteracts amyloid beta-mediated neurotoxicity. J Neurochem 2016;137:88-100. DOI PubMed

85. Yuyama K, Sun H, Usuki S, et al. A potential function for neuronal exosomes: sequestering intracerebral amyloid- $\beta$ peptide. FEBS Lett 2015;589:84-8. DOI PubMed

86. Katsuda T, Tsuchiya R, Kosaka N, et al. Human adipose tissue-derived mesenchymal stem cells secrete functional neprilysin-bound exosomes. Sci Rep 2013;3:1197. DOI PubMed PMC

87. Bulloj A, Leal MC, Xu H, Castaño EM, Morelli L. Insulin-degrading enzyme sorting in exosomes: a secretory pathway for a key brain amyloid-beta degrading protease. J Alzheimers Dis 2010;19:79-95. DOI PubMed PMC

88. Langui D, Girardot N, El Hachimi KH, et al. Subcellular Topography of Neuronal A $\beta$ Peptide in APPxPS1 Transgenic Mice. Am J Pathol 2004;165:1465-77. DOI PubMed PMC

89. Rajendran L, Honsho M, Zahn TR, et al. Alzheimer's disease beta-amyloid peptides are released in association with exosomes. Proc Natl Acad Sci U S A 2006;103:11172-7. DOI PubMed PMC

90. Vingtdeux V, Hamdane M, Loyens A, et al. Alkalizing drugs induce accumulation of amyloid precursor protein by-products in luminal vesicles of multivesicular bodies. J Biol Chem 2007;282:18197-205. DOI PubMed

91. Sullivan CP, Jay AG, Stack EC, et al. Retromer disruption promotes amyloidogenic APP processing. Neurobiol Dis 2011;43:338-45. DOI PubMed PMC

92. Dinkins MB, Dasgupta S, Wang G, Zhu G, Bieberich E. Exosome reduction in vivo is associated with lower amyloid plaque load in the 5XFAD mouse model of Alzheimer's disease. Neurobiol Aging 2014;35:1792-800. DOI PubMed PMC

93. Dinkins MB, Dasgupta S, Wang G, et al. The 5XFAD Mouse Model of Alzheimer's Disease Exhibits an Age-Dependent Increase in Anti-Ceramide IgG and Exogenous Administration of Ceramide Further Increases Anti-Ceramide Titers and Amyloid Plaque Burden. J Alzheimers Dis 2015;46:55-61. DOI PubMed PMC

94. Bellingham SA, Guo BB, Coleman BM, Hill AF. Exosomes: vehicles for the transfer of toxic proteins associated with neurodegenerative diseases? Front Physiol 2012;3:124. DOI PubMed PMC

95. Bolmont T, Haiss F, Eicke D, et al. Dynamics of the microglial/amyloid interaction indicate a role in plaque maintenance. $J$ Neurosci 2008;28:4283-92. DOI PubMed PMC

96. Hickman SE, Allison EK, El Khoury J. Microglial dysfunction and defective beta-amyloid clearance pathways in aging Alzheimer's disease mice. J Neurosci 2008;28:8354-60. DOI PubMed PMC

97. Song Z, Xu Y, Deng W, et al. Brain Derived Exosomes Are a Double-Edged Sword in Alzheimer's Disease. Front Mol Neurosci 


\section{0;13:79. DOI PubMed PMC}

98. Trotta T, Panaro MA, Cianciulli A, Mori G, Di Benedetto A, Porro C. Microglia-derived extracellular vesicles in Alzheimer's Disease: A double-edged sword. Biochem Pharmacol 2018;148:184-92. DOI PubMed

99. Saman S, Kim W, Raya M, et al. Exosome-associated tau is secreted in tauopathy models and is selectively phosphorylated in cerebrospinal fluid in early Alzheimer disease. J Biol Chem 2012;287:3842-9. DOI PubMed PMC

100. Guix FX, Corbett GT, Cha DJ, et al. Detection of Aggregation-Competent Tau in Neuron-Derived Extracellular Vesicles. Int J Mol Sci 2018;19:663. DOI PubMed PMC

101. Asai H, Ikezu S, Tsunoda S, et al. Depletion of microglia and inhibition of exosome synthesis halt tau propagation. Nat Neurosci 2015;18:1584-93. DOI PubMed PMC

102. Fiandaca MS, Kapogiannis D, Mapstone M, et al. Identification of preclinical Alzheimer's disease by a profile of pathogenic proteins in neurally derived blood exosomes: A case-control study. Alzheimers Dement 2015;11:600-7.e1. DOI PubMed PMC

103. Goetzl EJ, Mustapic M, Kapogiannis D, et al. Cargo proteins of plasma astrocyte-derived exosomes in Alzheimer's disease. FASEB J 2016;30:3853-9. DOI PubMed PMC

104. Zhuang X, Xiang X, Grizzle W, et al. Treatment of brain inflammatory diseases by delivering exosome encapsulated antiinflammatory drugs from the nasal region to the brain. Mol Ther 2011;19:1769-79. DOI PubMed PMC

105. Reich SG, Savitt JM. Parkinson's Disease. Med Clin North Am 2019;103:337-50. DOI PubMed

106. Olanow CW, Brundin P. Parkinson's disease and alpha synuclein: is Parkinson's disease a prion-like disorder? Mov Disord 2013;28:31-40. DOI PubMed

107. Emmanouilidou E, Melachroinou K, Roumeliotis T, et al. Cell-produced alpha-synuclein is secreted in a calcium-dependent manner by exosomes and impacts neuronal survival. J Neurosci 2010;30:6838-51. DOI PubMed PMC

108. Lee HJ, Patel S, Lee SJ. Intravesicular localization and exocytosis of alpha-synuclein and its aggregates. J Neurosci 2005;25:6016-24. DOI PubMed PMC

109. Alvarez-Erviti L, Seow Y, Schapira AH, et al. Lysosomal dysfunction increases exosome-mediated alpha-synuclein release and transmission. Neurobiol Dis 2011;42:360-7. DOI PubMed PMC

110. Cabin DE, Shimazu K, Murphy D, et al. Synaptic Vesicle Depletion Correlates with Attenuated Synaptic Responses to Prolonged Repetitive Stimulation in Mice Lacking $\alpha$-Synuclein. J Neurosci 2002;22:8797-807. PubMed PMC

111. Gedalya T, Loeb V, Israeli E, Altschuler Y, Selkoe DJ, Sharon R. Alpha-synuclein and polyunsaturated fatty acids promote clathrinmediated endocytosis and synaptic vesicle recycling. Traffic 2009;10:218-34. DOI PubMed PMC

112. Grey M, Dunning CJ, Gaspar R, et al. Acceleration of $\alpha$-synuclein aggregation by exosomes. J Biol Chem 2015;290:2969-82. DOI PubMed PMC

113. Stuendl A, Kunadt M, Kruse N, et al. Induction of $\alpha$-synuclein aggregate formation by CSF exosomes from patients with Parkinson's disease and dementia with Lewy bodies. Brain 2016;139:481-94. DOI PubMed PMC

114. Danzer KM, Kranich LR, Ruf WP, et al. Exosomal cell-to-cell transmission of alpha synuclein oligomers. Mol Neurodegener 2012;7:42. DOI PubMed PMC

115. Hornung S, Dutta S, Bitan G. CNS-Derived Blood Exosomes as a Promising Source of Biomarkers: Opportunities and Challenges. Front Mol Neurosci 2020;13:38. DOI PubMed PMC

116. Shi M, Liu C, Cook TJ, et al. Plasma exosomal $\alpha$-synuclein is likely CNS-derived and increased in Parkinson's disease. Acta Neuropathol 2014;128:639-50. DOI PubMed PMC

117. Si X, Tian J, Chen Y, Yan Y, Pu J, Zhang B. Central Nervous System-Derived Exosomal Alpha-Synuclein in Serum May Be a Biomarker in Parkinson's Disease. Neuroscience 2019;413:308-16. DOI PubMed

118. Jiang C, Hopfner F, Katsikoudi A, et al. Serum neuronal exosomes predict and differentiate Parkinson's disease from atypical parkinsonism. J Neurol Neurosurg Psychiatry 2020;91:720-9. DOI PubMed PMC

119. Niu M, Li Y, Li G, et al. A longitudinal study on $\alpha$-synuclein in plasma neuronal exosomes as a biomarker for Parkinson's disease development and progression. Eur J Neurol 2020;27:967-74. DOI PubMed

120. Haney MJ, Klyachko NL, Zhao Y, et al. Exosomes as drug delivery vehicles for Parkinson's disease therapy. J Control Release 2015;207:18-30. DOI PubMed PMC

121. Chen HX, Liang FC, Gu P, et al. Exosomes derived from mesenchymal stem cells repair a Parkinson's disease model by inducing autophagy. Cell Death Dis 2020;11:288. DOI PubMed PMC

122. Qu M, Lin Q, Huang L, et al. Dopamine-loaded blood exosomes targeted to brain for better treatment of Parkinson's disease. $J$ Control Release 2018;287:156-66. DOI PubMed

123. Bonda DJ, Manjila S, Mehndiratta P, et al. Human prion diseases: surgical lessons learned from iatrogenic prion transmission. Neurosurg Focus 2016;41:E10. DOI PubMed PMC

124. Fevrier B, Vilette D, Archer F, et al. Cells release prions in association with exosomes. Proc Natl Acad Sci U S A 2004;101:9683-8. DOI PubMed PMC

125. Alais S, Simoes S, Baas D, et al. Mouse neuroblastoma cells release prion infectivity associated with exosomal vesicles. Biol Cell 2008;100:603-15. DOI PubMed

126. Vilette D, Laulagnier K, Huor A, et al. Efficient inhibition of infectious prions multiplication and release by targeting the exosomal pathway. Cell Mol Life Sci 2015;72:4409-27. DOI PubMed

127. Guo BB, Bellingham SA, Hill AF. Stimulating the Release of Exosomes Increases the Intercellular Transfer of Prions. J Biol Chem 2016;291:5128-37. DOI PubMed PMC

128. Vella LJ, Sharples RA, Lawson VA, Masters CL, Cappai R, Hill AF. Packaging of prions into exosomes is associated with a novel 
pathway of PrP processing. J Pathol 2007;211:582-90. DOI PubMed

129. Cervenakova L, Saá P, Yakovleva O, et al. Are prions transported by plasma exosomes? Transfus Apher Sci 2016;55:70-83. DOI PubMed

130. Cheng L, Zhao W, Hill AF. Exosomes and their role in the intercellular trafficking of normal and disease associated prion proteins. Mol Aspects Med 2018;60:62-8. DOI PubMed

131. Kiernan MC, Vucic S, Cheah BC, et al. Amyotrophic lateral sclerosis. Lancet 2011;377:942-55. DOI PubMed

132. Brown RH, Al-Chalabi A. Amyotrophic Lateral Sclerosis. N Engl J Med 2017;377:162-72. DOI PubMed

133. Prasad A, Bharathi V, Sivalingam V, Girdhar A, Patel BK. Molecular Mechanisms of TDP-43 Misfolding and Pathology in Amyotrophic Lateral Sclerosis. Front Mol Neurosci 2019;12:25. DOI PubMed PMC

134. Zondler L, Feiler MS, Freischmidt A, et al. Impaired activation of ALS monocytes by exosomes. Immunol Cell Biol 2017;95:207-14. DOI PubMed

135. Grad LI, Pokrishevsky E, Silverman JM, Cashman NR. Exosome-dependent and independent mechanisms are involved in prion-like transmission of propagated Cu/Zn superoxide dismutase misfolding. Prion 2014;8:331-5. DOI PubMed PMC

136. Iguchi Y, Eid L, Parent M, et al. Exosome secretion is a key pathway for clearance of pathological TDP-43. Brain 2016;139:3187201. DOI PubMed PMC

137. Chen PC, Wu D, Hu CJ, Chen HY, Hsieh YC, Huang CC. Exosomal TAR DNA-binding protein-43 and neurofilaments in plasma of amyotrophic lateral sclerosis patients: A longitudinal follow-up study. J Neurol Sci 2020;418:117070. DOI PubMed

138. Calabria E, Scambi I, Bonafede R, et al. ASCs-Exosomes Recover Coupling Efficiency and Mitochondrial Membrane Potential in an. in vitro ;13:1070. DOI PubMed PMC

139. Pagan F, Torres-yaghi Y, Altshuler M. The diagnosis and natural history of Huntington disease. Handb Clin Neurol 2017;144:63-7. DOI PubMed

140. Wang JKT, Langfelder P, Horvath S, Palazzolo MJ. Exosomes and Homeostatic Synaptic Plasticity Are Linked to Each other and to Huntington's, Parkinson's, and Other Neurodegenerative Diseases by Database-Enabled Analyses of Comprehensively Curated Datasets. Front Neurosci 2017;11:149. DOI PubMed PMC

141. Jeon I, Cicchetti F, Cisbani G, et al. Human-to-mouse prion-like propagation of mutant huntingtin protein. Acta Neuropathol 2016;132:577-92. DOI PubMed PMC

142. Zhang X, Abels ER, Redzic JS, Margulis J, Finkbeiner S, Breakefield XO. Potential Transfer of Polyglutamine and CAG-Repeat RNA in Extracellular Vesicles in Huntington's Disease: Background and Evaluation in Cell Culture. Cell Mol Neurobiol 2016;36:459-70. DOI PubMed PMC

143. Díez-Planelles C, Sánchez-Lozano P, Crespo MC, et al. Circulating microRNAs in Huntington's disease: Emerging mediators in metabolic impairment. Pharmacol Res 2016;108:102-10. DOI PubMed

144. Kumar S, Vijayan M, Bhatti J, Reddy P. MicroRNAs as Peripheral Biomarkers in Aging and Age-Related Diseases. Prog Mol Biol Transl Sci 2017;146:47-94. DOI PubMed

145. Lee ST, Im W, Ban JJ, et al. Exosome-Based Delivery of miR-124 in a Huntington's Disease Model. J Mov Disord 2017;10:45-52. DOI PubMed PMC

146. Didiot MC, Hall LM, Coles AH, et al. Exosome-mediated Delivery of Hydrophobically Modified siRNA for Huntingtin mRNA Silencing. Mol Ther 2016;24:1836-47. DOI PubMed PMC

147. Moshé SL, Perucca E, Ryvlin P, Tomson T. Epilepsy: new advances. Lancet 2015;385:884-98. DOI PubMed

148. Betjemann JP, Lowenstein DH. Status epilepticus in adults. Lancet Neurol 2015;14:615-24. DOI PubMed

149. Batool A, Hill TDM, Nguyen NT, et al. Altered Biogenesis and MicroRNA Content of Hippocampal Exosomes Following Experimental Status Epilepticus. Front Neurosci 2019;13:1404. DOI PubMed PMC

150. Gitaí DLG, Dos Santos YDR, Upadhya R, Kodali M, Madhu LN, Shetty AK. Extracellular Vesicles in the Forebrain Display Reduced miR-346 and miR-331-3p in a Rat Model of Chronic Temporal Lobe Epilepsy. Mol Neurobiol 2020;57:1674-87. DOI PubMed

151. Yan S, Zhang H, Xie W, et al. Altered microRNA profiles in plasma exosomes from mesial temporal lobe epilepsy with hippocampal sclerosis. Oncotarget 2017;8:4136-46. DOI PubMed PMC

152. Chen SD, Pan HY, Huang JB, et al. Circulating MicroRNAs from Serum Exosomes May Serve as a Putative Biomarker in the Diagnosis and Treatment of Patients with Focal Cortical Dysplasia. Cells 2020;9:1867. DOI PubMed PMC

153. Long Q, Upadhya D, Hattiangady B, et al. Intranasal MSC-derived A1-exosomes ease inflammation, and prevent abnormal neurogenesis and memory dysfunction after status epilepticus. Proc Natl Acad Sci U S A 2017;114:E3536-45. DOI PubMed PMC

154. Nicholas R, Rashid W. Multiple sclerosis. Am Fam Physician 2013;87:712-4. PubMed

155. Galazka G, Mycko MP, Selmaj I, Raine CS, Selmaj KW. Multiple sclerosis: Serum-derived exosomes express myelin proteins. Mult Scler 2018;24:449-58. DOI PubMed

156. Pieragostino D, Cicalini I, Lanuti P, et al. Enhanced release of acid sphingomyelinase-enriched exosomes generates a lipidomics signature in CSF of Multiple Sclerosis patients. Sci Rep 2018;8:3071. DOI PubMed PMC

157. Kimura K, Hohjoh H, Fukuoka M, et al. Circulating exosomes suppress the induction of regulatory T cells via let-7i in multiple sclerosis. Nat Commun 2018;9:17. DOI PubMed PMC

158. Selmaj I, Cichalewska M, Namiecinska M, et al. Global exosome transcriptome profiling reveals biomarkers for multiple sclerosis. Ann Neurol 2017;81:703-17. DOI PubMed

159. Ebrahimkhani S, Vafaee F, Young PE, et al. Exosomal microRNA signatures in multiple sclerosis reflect disease status. Sci Rep 2017;7:14293. DOI PubMed PMC 
160. Manna I, Iaccino E, Dattilo V, et al. Exosome-associated miRNA profile as a prognostic tool for therapy response monitoring in multiple sclerosis patients. FASEB J 2018;32:4241-6. DOI PubMed

161. Wei Z, Fan B, Ding H, et al. Proteomics analysis of Schwann cell-derived exosomes: a novel therapeutic strategy for central nervous system injury. Mol Cell Biochem 2019;457:51-9. DOI PubMed PMC

162. Domingues HS, Falcão AM, Mendes-Pinto I, Salgado AJ, Teixeira FG. Exosome Circuitry During (De)(Re)Myelination of the Central Nervous System. Front Cell Dev Biol 2020;8:483. DOI PubMed PMC

163. Krämer-Albers EM, Bretz N, Tenzer S, et al. Oligodendrocytes secrete exosomes containing major myelin and stress-protective proteins: Trophic support for axons? Proteomics Clin Appl 2007;1:1446-61. DOI PubMed

164. Lopez-Verrilli MA, Picou F, Court FA. Schwann cell-derived exosomes enhance axonal regeneration in the peripheral nervous system. Glia 2013;61:1795-806. DOI PubMed

165. Hu M, Hong L, Liu C, et al. Electrical stimulation enhances neuronal cell activity mediated by Schwann cell derived exosomes. Sci Rep 2019;9:4206. DOI PubMed PMC

166. Bucan V, Vaslaitis D, Peck CT, Strauß S, Vogt PM, Radtke C. Effect of Exosomes from Rat Adipose-Derived Mesenchymal Stem Cells on Neurite Outgrowth and Sciatic Nerve Regeneration After Crush Injury. Mol Neurobiol 2019;56:1812-24. DOI PubMed PMC

167. Xiao Y, Geng F, Wang G, Li X, Zhu J, Zhu W. Bone marrow-derived mesenchymal stem cells-derived exosomes prevent oligodendrocyte apoptosis through exosomal miR-134 by targeting caspase-8. J Cell Biochem ;2018:2109-18. DOI PubMed

168. Thomi G, Joerger-Messerli M, Haesler V, Muri L, Surbek D, Schoeberlein A. Intranasally Administered Exosomes from Umbilical Cord Stem Cells Have Preventive Neuroprotective Effects and Contribute to Functional Recovery after Perinatal Brain Injury. Cells 2019;8:855. DOI PubMed PMC

169. Otero-Ortega L, Laso-García F, Gómez-de Frutos M, et al. Role of Exosomes as a Treatment and Potential Biomarker for Stroke. Transl Stroke Res 2019;10:241-9. DOI PubMed

170. Zhang ZG, Chopp M. Exosomes in stroke pathogenesis and therapy. J Clin Invest 2016;126:1190-7. DOI PubMed PMC

171. Xin H, Li Y, Buller B, et al. Exosome-mediated transfer of miR-133b from multipotent mesenchymal stromal cells to neural cells contributes to neurite outgrowth. Stem Cells 2012;30:1556-64. DOI PubMed PMC

172. Chen F, Du Y, Esposito E, et al. Effects of Focal Cerebral Ischemia on Exosomal Versus Serum miR126. Transl Stroke Res 2015;6:478-84. DOI PubMed

173. Yang J, Zhang X, Chen X, Wang L, Yang G. Exosome Mediated Delivery of miR-124 Promotes Neurogenesis after Ischemia. Mol Ther Nucleic Acids 2017;7:278-87. DOI PubMed PMC

174. Seifert HA, Offner H. The splenic response to stroke: from rodents to stroke subjects. J Neuroinflammation 2018;15:195. DOI PubMed PMC

175. Makin SD, Cook FA, Dennis MS, Wardlaw JM. Cerebral small vessel disease and renal function: systematic review and metaanalysis. Cerebrovasc Dis 2015;39:39-52. DOI PubMed PMC

176. Zhang G, Chen L, Guo X, et al. Comparative Analysis of microRNA Expression Profiles of Exosomes Derived from Normal and Hypoxic Preconditioning Human Neural Stem Cells by Next Generation Sequencing. J Biomed Nanotechnol 2018;14:1075-89. DOI PubMed

177. Li DB, Liu JL, Wang W, et al. Plasma Exosomal miRNA-122-5p and miR-300-3p as Potential Markers for Transient Ischaemic Attack in Rats. Front Aging Neurosci 2018;10:24. DOI PubMed PMC

178. Datta A, Chen CP, Sze SK. Discovery of prognostic biomarker candidates of lacunar infarction by quantitative proteomics of microvesicles enriched plasma. PLoS One 2014;9:e94663. DOI PubMed PMC

179. Kanhai DA, de Kleijn DP, Kappelle LJ, et al; SMART Study Group. Extracellular vesicle protein levels are related to brain atrophy and cerebral white matter lesions in patients with manifest vascular disease: the SMART-MR study. BMJ Open 2014;4:e003824. DOI PubMed PMC

180. Ji Q, Ji Y, Peng J, et al. Increased Brain-Specific MiR-9 and MiR-124 in the Serum Exosomes of Acute Ischemic Stroke Patients. PLoS One 2016;11:e0163645. DOI PubMed PMC

181. Li DB, Liu JL, Wang W, et al. Plasma Exosomal miR-422a and miR-125b-2-3p Serve as Biomarkers for Ischemic Stroke. Curr Neurovasc Res 2017;14:330-7. DOI PubMed

182. Chen Y, Song Y, Huang J, et al. Increased Circulating Exosomal miRNA-223 Is Associated with Acute Ischemic Stroke. Front Neurol 2017;8:57. DOI PubMed PMC

183. Wang W, Li DB, Li RY, et al. Diagnosis of Hyperacute and Acute Ischaemic Stroke: The Potential Utility of Exosomal MicroRNA21-5p and MicroRNA-30a-5p. Cerebrovasc Dis 2018;45:204-12. DOI PubMed

184. McKee CA, Lukens JR. Emerging Roles for the Immune System in Traumatic Brain Injury. Front Immunol 2016;7:556. DOI PubMed PMC

185. Taylor DD, Gercel-Taylor C. Exosome platform for diagnosis and monitoring of traumatic brain injury. Philos Trans R Soc Lond B Biol Sci 2014;369:20130503. DOI PubMed PMC

186. Huang S, Ge X, Yu J, et al. Increased miR-124-3p in microglial exosomes following traumatic brain injury inhibits neuronal

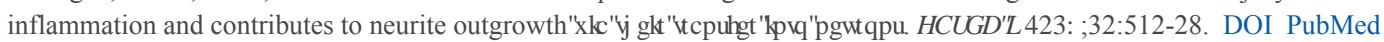

187. Guedes VA, Kenney K, Shahim P, et al; CENC Multisite Observational Study Investigators. Exosomal neurofilament light: A prognostic biomarker for remote symptoms after mild traumatic brain injury? Neurology 2020;94:e2412-23. DOI PubMed PMC

188. Goetzl EJ, Elahi FM, Mustapic M, et al. Altered levels of plasma neuron-derived exosomes and their cargo proteins characterize acute and chronic mild traumatic brain injury. FASEB J 2019;33:5082-8. DOI PubMed PMC 
189. Beard K, Meaney DF, Issadore D. Clinical Applications of Extracellular Vesicles in the Diagnosis and Treatment of Traumatic Brain Injury. J Neurotrauma 2020;37:2045-56. DOI PubMed PMC

190. Gruzdev SK, Yakovlev AA, Druzhkova TA, Guekht AB, Gulyaeva NV. The Missing Link: How Exosomes and miRNAs can Help in Bridging Psychiatry and Molecular Biology in the Context of Depression, Bipolar Disorder and Schizophrenia. Cell Mol Neurobiol 2019;39:729-50. DOI PubMed

191. Baudry A, Mouillet-Richard S, Schneider B, Launay JM, Kellermann O. miR-16 targets the serotonin transporter: a new facet for adaptive responses to antidepressants. Science 2010;329:1537-41. DOI PubMed

192. Beveridge NJ, Tooney PA, Carroll AP, et al. Dysregulation of miRNA $181 \mathrm{~b}$ in the temporal cortex in schizophrenia. Hum Mol Genet 2008;17:1156-68. DOI PubMed

193. Muiños-Gimeno M, Espinosa-Parrilla Y, Guidi M, et al. Human microRNAs miR-22, miR-138-2, miR-148a, and miR-488 are associated with panic disorder and regulate several anxiety candidate genes and related pathways. Biol Psychiatry 2011;69:526-33. DOI PubMed

194. Rong H, Liu TB, Yang KJ, et al. MicroRNA-134 plasma levels before and after treatment for bipolar mania. J Psychiatr Res 2011;45:92-5. DOI PubMed

195. Banigan MG, Kao PF, Kozubek JA, et al. Differential expression of exosomal microRNAs in prefrontal cortices of schizophrenia and bipolar disorder patients. PLoS One 2013;8:e48814. DOI PubMed PMC

196. Du Y, Yu Y, Hu Y, et al. Genome-Wide, Integrative Analysis Implicates Exosome-Derived MicroRNA Dysregulation in Schizophrenia. Schizophr Bull 2019;45:1257-66. DOI PubMed PMC

197. Lee ST, Chu K, Jung KH, et al. miR-206 regulates brain-derived neurotrophic factor in Alzheimer disease model. Ann Neurol 2012;72:269-77. DOI PubMed

198. role of microRNAs in major depressive disorder: diagnosis and therapeutic implications. Dialogues Clin Neurosci 2014;16:43-61. PubMed PMC

199. Liang JQ, Liao HR, Xu CX, et al. Serum Exosome-Derived miR-139-5p as a Potential Biomarker for Major Depressive Disorder. Neuropsychiatr Dis Treat 2020;16:2689-93. DOI PubMed PMC

200. Wen PY, Weller M, Lee EQ, et al. Glioblastoma in adults: a Society for Neuro-Oncology (SNO) and European Society of NeuroOncology (EANO) consensus review on current management and future directions. Neuro Oncol 2020;22:1073-113. DOI PubMed PMC

201. Davis ME. Glioblastoma: Overview of Disease and Treatment. Clin J Oncol Nurs 2016;20:S2-8. DOI PubMed PMC

202. Stupp R, Hegi ME, Mason WP, et al. Effects of radiotherapy with concomitant and adjuvant temozolomide versus radiotherapy alone on survival in glioblastoma in a randomised phase III study: 5-year analysis of the EORTC-NCIC trial. Lancet Oncol 2009;10:45966. DOI PubMed

203. Patel AP, Tirosh I, Trombetta JJ, et al. Single-cell RNA-seq highlights intratumoral heterogeneity in primary glioblastoma. Science 2014;344:1396-401. DOI PubMed PMC

204. Galli R, Binda E, Orfanelli U, et al. Isolation and characterization of tumorigenic, stem-like neural precursors from human glioblastoma. Cancer Res 2004;64:7011-21. DOI PubMed

205. Chen J, Li Y, Yu TS, et al. A restricted cell population propagates glioblastoma growth after chemotherapy. Nature 2012;488:522-6. DOI PubMed PMC

206. Singh SK, Hawkins C, Clarke ID, et al. Identification of human brain tumour initiating cells. Nature 2004;432:396-401. DOI PubMed

207. Oushy S, Hellwinkel JE, Wang M, et al. Glioblastoma multiforme-derived extracellular vesicles drive normal astrocytes towards a tumour-enhancing phenotype. Philos Trans R Soc Lond B Biol Sci 2018;373:20160477. DOI PubMed PMC

208. Gao X, Zhang Z, Mashimo T, et al. Gliomas Interact with Non-glioma Brain Cells via Extracellular Vesicles. Cell Rep 2020;30:24892500.e5. DOI PubMed

209. Mondal A, Kumari Singh D, Panda S, Shiras A. Extracellular Vesicles As Modulators of Tumor Microenvironment and Disease Progression in Glioma. Front Oncol 2017;7:144. DOI PubMed PMC

210. Shao H, Chung J, Lee K, et al. Chip-based analysis of exosomal mRNA mediating drug resistance in glioblastoma. Nat Commun 2015;6:6999. DOI PubMed PMC

211. Skog J, Würdinger T, van Rijn S, et al. Glioblastoma microvesicles transport RNA and proteins that promote tumour growth and provide diagnostic biomarkers. Nat Cell Biol 2008;10:1470-6. DOI PubMed PMC

212. Simon T, Jackson E, Giamas G. Breaking through the glioblastoma micro-environment via extracellular vesicles. Oncogene 2020;39:4477-90. DOI PubMed PMC

213. Treps L, Perret R, Edmond S, Ricard D, Gavard J. Glioblastoma stem-like cells secrete the pro-angiogenic VEGF-A factor in extracellular vesicles. J Extracell Vesicles 2017;6:1359479. DOI PubMed PMC

214. Sun X, Ma X, Wang J, et al. Glioma stem cells-derived exosomes promote the angiogenic ability of endothelial cells through miR21/VEGF signal. Oncotarget 2017;8:36137-48. DOI PubMed PMC

215. Wang ZF, Liao F, Wu H, Dai J. Glioma stem cells-derived exosomal miR-26a promotes angiogenesis of microvessel endothelial cells in glioma. J Exp Clin Cancer Res 2019;38:201. DOI PubMed PMC

216. Liu S, Sun J, Lan Q. Glioblastoma microvesicles promote endothelial cell proliferation through Akt/beta-catenin pathway. Int J Clin Exp Pathol 2014;7:4857-66. PubMed PMC

217. Al-Nedawi K, Meehan B, Micallef J, et al. Intercellular transfer of the oncogenic receptor EGFRvIII by microvesicles derived from tumour cells. Nat Cell Biol 2008;10:619-24. DOI PubMed 
218. Antonyak MA, Li B, Boroughs LK, et al. Cancer cell-derived microvesicles induce transformation by transferring tissue transglutaminase and fibronectin to recipient cells. Proc Natl Acad Sci U S A 2011;108:4852-7. DOI PubMed PMC

219. Lang HL, Hu GW, Chen Y, et al. Glioma cells promote angiogenesis through the release of exosomes containing long non-coding RNA POU3F3. Eur Rev Med Pharmacol Sci 2017;21:959-72. PubMed

220. Lang HL, Hu GW, Zhang B, et al. Glioma cells enhance angiogenesis and inhibit endothelial cell apoptosis through the release of exosomes that contain long non-coding RNA CCAT2. Oncol Rep 2017;38:785-98. DOI PubMed PMC

221. Bronisz A, Wang Y, Nowicki MO, et al. Extracellular vesicles modulate the glioblastoma microenvironment via a tumor suppression signaling network directed by miR-1. Cancer Res 2014;74:738-50. DOI PubMed PMC

222. Verhaak RG, Hoadley KA, Purdom E, et al; Cancer Genome Atlas Research Network. Integrated genomic analysis identifies clinically relevant subtypes of glioblastoma characterized by abnormalities in PDGFRA, IDH1, EGFR, and NF1. Cancer Cell 2010;17:98-110. DOI PubMed PMC

223. Suvà ML, Rheinbay E, Gillespie SM, et al. Reconstructing and reprogramming the tumor-propagating potential of glioblastoma stemlike cells. Cell 2014;157:580-94. DOI PubMed PMC

224. Berenguer J, Lagerweij T, Zhao XW, et al. Glycosylated extracellular vesicles released by glioblastoma cells are decorated by CCL18 allowing for cellular uptake via chemokine receptor CCR8. J Extracell Vesicles 2018;7:1446660. DOI PubMed PMC

225. Lucero R, Zappulli V, Sammarco A, et al. Glioma-Derived miRNA-Fontaining Extracellular Vesicles Induce Angiogenesis by Reprogramming Brain Endothelial Cells. Cell Rep 2020;30:2065-74.e4. DOI PubMed PMC

226. Spinelli C, Montermini L, Meehan B, et al. Molecular subtypes and differentiation programmes of glioma stem cells as determinants of extracellular vesicle profiles and endothelial cell-stimulating activities. J Extracell Vesicles 2018;7:1490144. DOI PubMed PMC

227. Wei Z, Batagov AO, Schinelli S, et al. Coding and noncoding landscape of extracellular RNA released by human glioma stem cells. Nat Commun 2017;8:1145. DOI PubMed PMC

228. Hallal S, Mallawaaratchy DM, Wei H, et al. Extracellular Vesicles Released by Glioblastoma Cells Stimulate Normal Astrocytes to Acquire a Tumor-Supportive Phenotype Via p53 and MYC Signaling Pathways. Mol Neurobiol 2019;56:4566-81. DOI PubMed $\mathrm{PMC}$

229. Colangelo NW, Azzam EI. Extracellular vesicles originating from glioblastoma cells increase metalloproteinase release by astrocytes: the role of CD147 (EMMPRIN) and ionizing radiation. Cell Commun Signal 2020;18:21. DOI PubMed PMC

230. Zeng A, Wei Z, Rabinovsky R, et al. Glioblastoma-Derived Extracellular Vesicles Facilitate Transformation of Astrocytes via Reprogramming Oncogenic Metabolism. iScience 2020;23:101420. DOI PubMed PMC

231. van der Vos KE, Abels ER, Zhang X, et al. Directly visualized glioblastoma-derived extracellular vesicles transfer RNA to microglia/macrophages in the brain. Neuro Oncol 2016;18:58-69. DOI PubMed PMC

232. de Vrij J, Maas SL, Kwappenberg KM, et al. Glioblastoma-derived extracellular vesicles modify the phenotype of monocytic cells. Int J Cancer 2015;137:1630-42. DOI PubMed

233. Harshyne LA, Nasca BJ, Kenyon LC, Andrews DW, Hooper DC. Serum exosomes and cytokines promote a T-helper cell type 2 environment in the peripheral blood of glioblastoma patients. Neuro Oncol 2016;18:206-15. DOI PubMed PMC

234. Abels ER, Maas SLN, Nieland L, et al. Glioblastoma-Associated Microglia Reprogramming Is Mediated by Functional Transfer of Extracellular miR-21. Cell Rep 2019;28:3105-3119.e7. DOI PubMed PMC

235. Gabrusiewicz K, Li X, Wei J, et al. Glioblastoma stem cell-derived exosomes induce M2 macrophages and PD-L1 expression on human monocytes. Oncoimmunology 2018;7:e1412909. DOI PubMed PMC

236. Grimaldi A, Serpe C, Chece G, et al. Microglia-Derived Microvesicles Affect Microglia Phenotype in Glioma. Front Cell Neurosci 2019;13:41. DOI PubMed PMC

237. Ricklefs FL, Alayo Q, Krenzlin H, et al. Immune evasion mediated by PD-L1 on glioblastoma-derived extracellular vesicles. Sci Adv 2018;4:eaar2766. DOI PubMed PMC

238. Munoz JL, Rodriguez-Cruz V, Ramkissoon SH, Ligon KL, Greco SJ, Rameshwar P. Temozolomide resistance in glioblastoma occurs by miRNA-9-targeted PTCH1, independent of sonic hedgehog level. Oncotarget 2015;6:1190-201. DOI PubMed PMC

239. Munoz JL, Bliss SA, Greco SJ, Ramkissoon SH, Ligon KL, Rameshwar P. Delivery of Functional Anti-miR-9 by Mesenchymal Stem Cell-derived Exosomes to Glioblastoma Multiforme Cells Conferred Chemosensitivity. Mol Ther Nucleic Acids 2013;2:e126. DOI PubMed PMC

240. Chuang HY, Su YK, Liu HW, et al. Preclinical Evidence of STAT3 Inhibitor Pacritinib Overcoming Temozolomide Resistance via Downregulating miR-21-Enriched Exosomes from M2 Glioblastoma-Associated Macrophages. J Clin Med 2019;8:959. DOI PubMed PMC

241. Figueroa JM, Skog J, Akers J, et al. Detection of wild-type EGFR amplification and EGFRvIII mutation in CSF-derived extracellular vesicles of glioblastoma patients. Neuro Oncol 2017;19:1494-502. DOI PubMed PMC

242. Akers JC, Ramakrishnan V, Kim R, et al. MiR-21 in the extracellular vesicles (EVs) of cerebrospinal fluid (CSF): a platform for glioblastoma biomarker development. PLoS One 2013;8:e78115. DOI PubMed PMC

243. Akers JC, Ramakrishnan V, Kim R, et al. miRNA contents of cerebrospinal fluid extracellular vesicles in glioblastoma patients. $J$ Neurooncol 2015;123:205-16. DOI PubMed PMC 